Review

\title{
High Birefringence Liquid Crystals
}

\author{
Roman Dąbrowski *, Przemysław Kula and Jakub Herman \\ Institute of Chemistry, Military University of Technology, Warsaw 00-908, Poland; \\ E-Mails: pkula@wat.edu.pl (P.K.); jherman@wat.edu.pl (J.H.) \\ * Author to whom correspondence should be addressed; E-Mail: rdabrowski@wat.edu.pl; \\ Tel.: +48-22-583-96-07; Fax: +48-22-683-95-82.
}

Received: 28 June 2013; in revised form: 27 July 2013 / Accepted: 31 July 2013 /

Published: 3 September 2013

\begin{abstract}
Liquid crystals, compounds and mixtures with positive dielectric anisotropies are reviewed. The mesogenic properties and physical chemical properties (viscosity, birefringence, refractive indices, dielectric anisotropy and elastic constants) of compounds being cyano, fluoro, isothiocyanato derivatives of biphenyl, terphenyl, quaterphenyl, tolane, phenyl tolane, phenyl ethynyl tolane, and biphenyl tolane are compared. The question of how to obtain liquid crystal with a broad range of nematic phases is discussed in detail. Influence of lateral substituent of different kinds of mesogenic and physicochemical properties is presented (demonstrated). Examples of mixtures with birefringence $\Delta n$ in the range of $0.2-0.5$ are given.
\end{abstract}

Keywords: liquid crystal; cyanide; fluoride; isothiocyanate; biphenyl; tolane; terphenyl; quaterphenyl; high birefringence; positive dielectric anisotropy

\section{Introduction}

\subsection{Applications of High Birefringence Liquid Crystals (LCs)}

Low and medium birefringence nematic LCs $(\Delta n=0.09 / 0.12)$ are still most important for display applications [1-7]. They are used in large TV screens and computer monitors, and also in smaller flat panels of mobile phones, automotive devices and projectors. During the last decade, response times have continuously improved, from $25 \mathrm{~ms}$ to only $3 \mathrm{~ms}$ and even below [4]. Reduction of the cell gap from $5 \mu \mathrm{m}$ to $3 \mu \mathrm{m}$ is only partially responsible for this effect. This reduction in response times can largely be attributed to the generation of new liquid crystal mixtures. One of the most important 
methods for their formulation is mixing polar higher birefringence compounds with nonpolar low birefringence hydrocarbons having very small rotational viscosity [8].

Color sequential LCDs (liquid crystal displays) produce better quality picture [9-11], but they need fast operating materials, which can be ensured only by the high birefringence LCs with low viscosity, in combination with a small gap [11].

Currently new types of liquid crystal displays and devices are considered, wherein response times may be less than $1 \mathrm{~ms}$. For this purpose, "blue phase" mode [12-14] or other cholesteric modes [15] are proposed and also, LCs with higher $\Delta n$ are needed. The main area of application for very high birefringence LC is in infrared spectral range [16-18] and recently, the interest is also gained to $\mathrm{GHz}$ and $\mathrm{THz}$ ranges. They are connected with telecommunication devices needs or nondestructive microwaves apparatus to control goods and people [19], cholesteric lasers [20,21], manufacturing tunable metamaterial [22-25]. Different devices such as tunable spatial modulators for light and laser beam steering and for holography [26-33], switchable phase shifters [34-36], various types of tunable filters which select or remove bands [37-40], tunable capacitors [41], antennas [42], lenses [43,44] were manufactured, and others such as photonic fiber [45] (see also, for more information, reviewed papers [46,47]). For these purposes, different high birefringence materials from 0.2 to more than 0.5 are now available [48-52], but further development and improvement of their properties is still necessary. To reanalyze the experimental results that have been obtained so far may be helpful for this task.

\subsection{Requirement for Liquid Crystal Molecules}

Practically, only multicomponent mixtures are used. The components must be carefully selected in order to obtain the desired temperature range of the nematic phase with optimal birefringence $(\Delta n)$, elastic constants $\left(k_{\mathrm{ii}}\right)$ positive or negative dielectric anisotropy $(\Delta \varepsilon)$, high chemical and photochemical stability and high resistivity (or high voltage holding ratio (VHR)). The molecules with low melting point, low melting enthalpy, low viscosity (the most important is rotational viscosity $\gamma$ ) and direct transition from the crystal phase to nematic phase are the most necessary, see Figure 1.

Some compounds with smectic phase may be also utilized but usually in limited amounts. Some cases were demonstrated where smectic phases were strongly destabilized and the range of nematic phase was enhanced, or nematic phase was created only from smectic compounds. That could be noticed in isothiocyanates mixtures (smectic $\mathrm{A}_{1}$ ) $[53,54]$ and mixtures of isothiocyanates (smectic $\mathrm{A}_{1}$ or smectic E) and cyanides (smectic $A_{d}$ ) [55-57]. Both components are polar and must differ with the lengths of molecules meaningfully. Among the mixtures there consisted polar and nonpolar compounds, and very often a strong induction of orthogonal smectic A and/or B phases was observed [58-60].

The molecules which differ in shapes (different length of rigid cores or chains, or different breadth also) have the ability to form eutectic mixtures. They should be ideally miscible in the nematic phase and totally immiscible in the solid phase. The latter results in a solid phase consisting of separated crystals of pure compounds. In such a case, we observe that the mixture melts at a much lower temperature than the pure components (see Figure 2). 
Figure 1. Phase transitions in mesogenic molecules and observed texture under polarization microscope for the SmA phase and $\mathrm{N}$ phase as an example. The observed range of value for the enthalpy changes during transitions is also given.

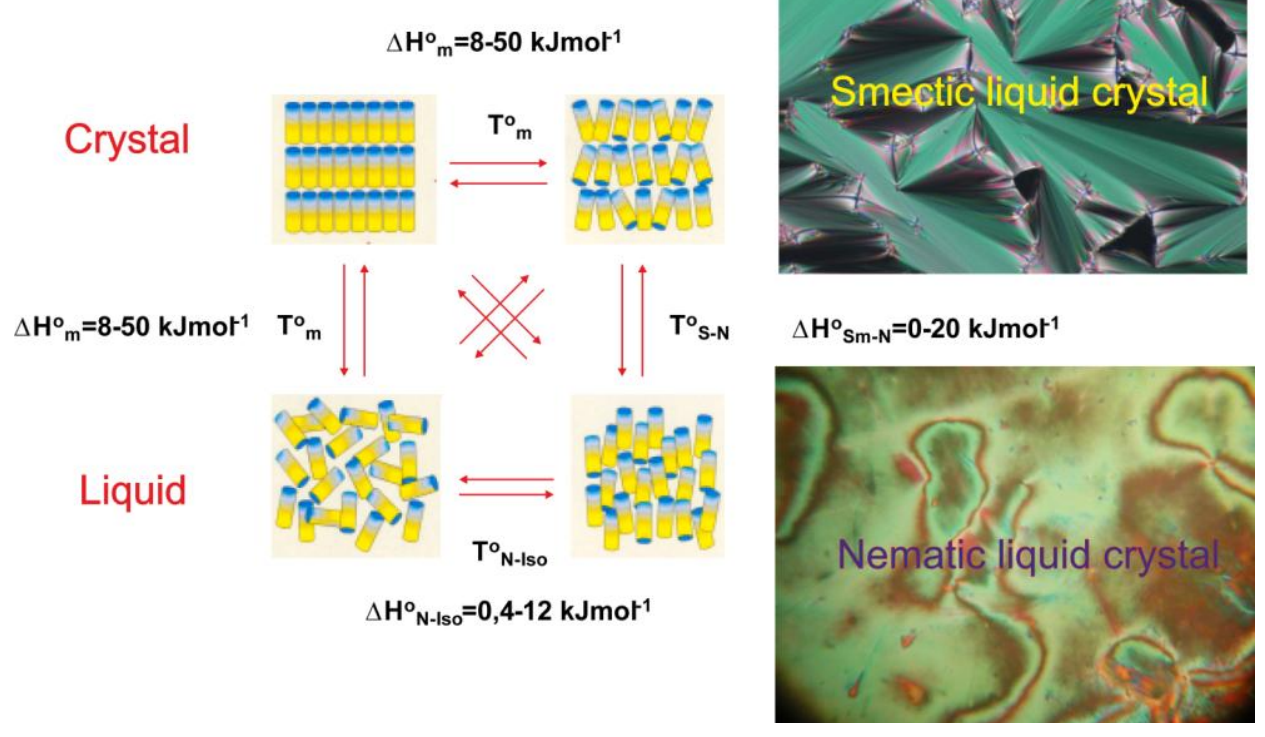

Figure 2. Phase diagram - theoretical miscibility curves of compound A and compound B (or $\mathrm{A}^{\prime}$ and $\mathrm{B}^{\prime}$ ) in their nematic phase for the case of total immiscibility of these compounds in the solid phase and ideal miscibility in the nematic phase. For binary system A and B at eutectic point, components A and B melt together. Distinct from the eutectic composition by heating, only at first, one component is melting, hereafter reaching the eutectic composition, both $\mathrm{A}$ and $\mathrm{B}$ are melting at eutectic ratio. The compounds have the following parameters: $T_{m}(\mathrm{~A})=140{ }^{\circ} \mathrm{C}$ and $\Delta H_{m}(\mathrm{~A})=24 \mathrm{~kJ} / \mathrm{mol}$ or $\Delta H_{m}\left(\mathrm{~A}^{\prime}\right)=16 \mathrm{~kJ} / \mathrm{mol}$; $T_{m}(\mathrm{~B})=120^{\circ} \mathrm{C}$ and $\Delta H_{m}(\mathrm{~B})=20 \mathrm{~kJ} / \mathrm{mol}$ or $T_{m}\left(\mathrm{~B}^{\prime}\right)=100{ }^{\circ} \mathrm{C}$ and $\Delta H_{m}\left(\mathrm{~B}^{\prime}\right)=20 \mathrm{~kJ} / \mathrm{mol}$.

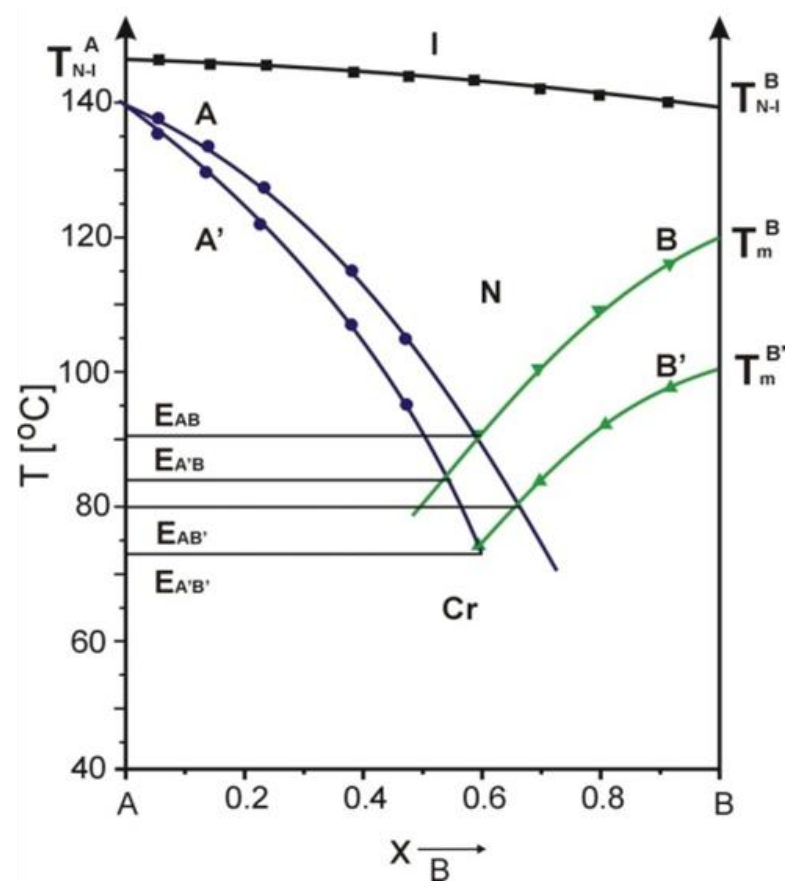


With the lower melting temperatures $T_{m}$ of the mixture components together with the low values of melting enthalpies, a lower melting point for the eutectic mixture is observed. The composition of $k$-component eutectic mixture and its melting temperature may be calculated from the Equations (1) and (2), if the data of the pure components is known:

$$
\begin{gathered}
\ln x_{k}=-\frac{\Delta H_{m}^{k}}{R}\left(\frac{1}{T}-\frac{1}{T_{m}^{k}}\right) \\
\sum_{k=1}^{n} x_{k}=1
\end{gathered}
$$

$x_{k}$ - the mole ratio of $k$-component; $\Delta H_{m}{ }^{k}$ melting enthalpy; and $T_{m}{ }^{k}$ melting temperature of the pure $k$-component respectively; $R$ gas constant.

The Equation (1) has a more complex form [61] if a transition in the solid phase is observed.

Also, when a partial miscibility of the components in solid phase occurs, the phase diagram of such a mixture has a more complex form and the drop in melting point is smaller or even not observed at all for an ideal miscibility of components in the solid phase or when solid complexes arise [62].

Retardation of light rays or phase shift $\phi$ is related to the birefringence $\Delta n$ as follows:

$$
\Delta \phi=2 \pi \Delta n \cdot d / \lambda=2 \pi \Delta n \cdot d(f / c)
$$

where $d$ cell gap; $\lambda$-wavelength; $f$ - frequency of wave; $c$ - speed of light.

The larger $\Delta n$ is, the larger the phase shift obtained. High value of birefringence is especially important for devices working in infrared or $\mathrm{THz}$ range of electromagnetic radiation because the lengths of waves are much longer there than in visible range. In transmissive devices, when working in ECB (VA) or IPS modes, the condition $d \cdot \Delta n=\lambda / 2$ (half plate) must be met during TN mode $d \cdot \Delta n=\sqrt{3} \lambda / 2$. The larger $\Delta n$ is, a smaller cell gap $(d)$ may be used and faster operating devices can be obtained, see Equations (4) and (5).

$$
\begin{gathered}
\tau_{o f f} \propto \frac{\gamma_{1} \cdot d^{2}}{k_{i i}} \\
\tau_{o n}=\frac{\gamma_{1} \cdot d^{2}}{k_{i i}\left(V / V_{t h}-1\right)}=\frac{\tau_{o f f}}{\left(V / V_{t h}\right)^{2}-1}
\end{gathered}
$$

Electric field involves a reorientation of the molecules with the time $\tau_{o n}$, which depends in a quadratic way on the cell gap $(d)$, which is shorter for LCs with lower rotational viscosity and larger elastic constant $k_{i i}$. For different electrooptic modes, different elastic constants are taken into account as decisively ( $k_{33}$ for VAN or ECB, $k_{22}$ for IPS and $K_{T N}=k_{11}+\left(k_{33}-2 k_{22}\right) / 4$ for TN). In devices addressed by one frequency, the decay time $\tau_{\text {off }}$, as being only a pure relaxation process, is longer than the rise time $\left(\tau_{\text {off }}>\tau_{\text {on }}\right)$.

The time $\tau_{o n}$ may be effectively shortened by using higher voltage $(\mathrm{V})$ and liquid crystals with a lower threshold voltage $\left(V_{t h}\right)$. The latter is the lower as the higher is dielectric anisotropy $\Delta \varepsilon$ of LCs. Symmetrization of the response times $\left[\tau_{\text {off }} \sim \tau_{\text {on }}\right.$ ] may be obtained by using a dual frequency [63].

To estimate which liquid crystal mixtures or compounds are better for preparations, instead of making a comparison of their individual parameters: $\Delta n, k_{11}, \gamma, V_{t h}$, the more effective way is to compare their combined features defined by a more complex parameter called Figure of Merits (FoMs) [49,50,64]. 
The most popular are the following:

$$
\begin{gathered}
F o M_{1}=\frac{\Delta n^{2} \cdot k_{i i}}{\gamma_{1}} \\
F o M_{2}=\frac{\Delta n^{2} \cdot k_{i i}}{\gamma_{1} V_{t h}} \\
F o M_{3}=\frac{\gamma_{1}}{\Delta n^{2} \cdot T_{N-I}}
\end{gathered}
$$

Liquid crystal compounds and mixtures with large values of $F o M_{1}$ and $F o M_{2}$ and compounds with a small value of $\mathrm{FoM}_{3}$ are desired.

\section{Basics for the Design of High Birefringence LCs Molecules and Optimizing Their Properties}

Liquid crystalline molecules with large anisotropy of the electron polarizability $\alpha_{\mathrm{e}}$, which is involved by the presence of the long conjugated $\pi$ electron system of bonds, have high birefringence. The most profitable are molecules with large length to breadth ratio and rigid cores composed of aromatic rings. The best ones comprise of benzene rings connected directly, or better, via the ethynyl $(-\mathrm{C} \equiv \mathrm{C}-)$ bridge, see Figure 3 .

Figure 3. The most useful rigid cores for designing high birefringence liquid crystal molecules. Input to the birefringence: benzene ring $\sim 0.09$, triple bond $\sim 0.07$.



A single benzene ring brings a contribution to the birefringence of about 0.09 and the ethynyl bridge of 0.07 . Connected benzene rings, especially via triple bonds, give an input to $\Delta n$ which is more than the total contribution of the individual units, due to improvement in the conjugation conditions of $\pi$ electrons. For molecules consisted of three benzene rings, estimated $\Delta n$ is about 0.27 and still comprising in addition two $-\mathrm{C} \equiv \mathrm{C}$ - bridges estimated $\Delta n$ reaches of 0.41 . The above mentioned molecules, which consisted only of the rigid core (Figure 3), have high melting points. Two or more rings creating the rigid core of compounds are yet to bring any mesogenic properties. Nematic phase is virtually observed in four ring quarter phenyls at a temperature much lower than the melting point. 
For quinquephenyl (five-ring) compounds, an enantiotropic nematic phase is observed. It has the transitions: Cr $386.5 \mathrm{~N} 415$ Iso, and has not only a very high melting point but also a very high melting enthalpy (42.3 $\mathrm{kJ} \mathrm{mol}^{-1}$ ) [65]. Joining alkyl or alkoxy chains into these molecules depresses their melting points and mesophases are seen above the melting points in most cases. Introducing a naphthalene ring or a heterocyclic ring such as pyridine or pyrimidine or thiopheneto, the conjugated system may sometimes increase the nematic character of the compounds, but such compounds usually have much higher viscosity. Using other bridges enabling effective conjugation of $\pi$ electrons among the rings such as $-\mathrm{C} \equiv \mathrm{C}-\mathrm{C} \equiv \mathrm{C}-$ or $-\mathrm{CH}=\mathrm{CH}-\mathrm{C} \equiv \mathrm{CH}-$ causes the compounds to be photo-chemically unstable (they easily polymerize), while the $-\mathrm{HC}=\mathrm{N}-$ bridge makes the compounds chemically unstable (these easily hydrolyze). In compounds with ethylene $(-\mathrm{CH}=\mathrm{CH}-)$ and azo $(-\mathrm{N}=\mathrm{N}-)$ bridges, cis-trans isomerization is observed under influence of light, see Figure 4.

Figure 4. Reverse trans-cis isomerization is involved by the light absorption of different lengths, Ar-aryl (phenyl, naphtyl and etc.).

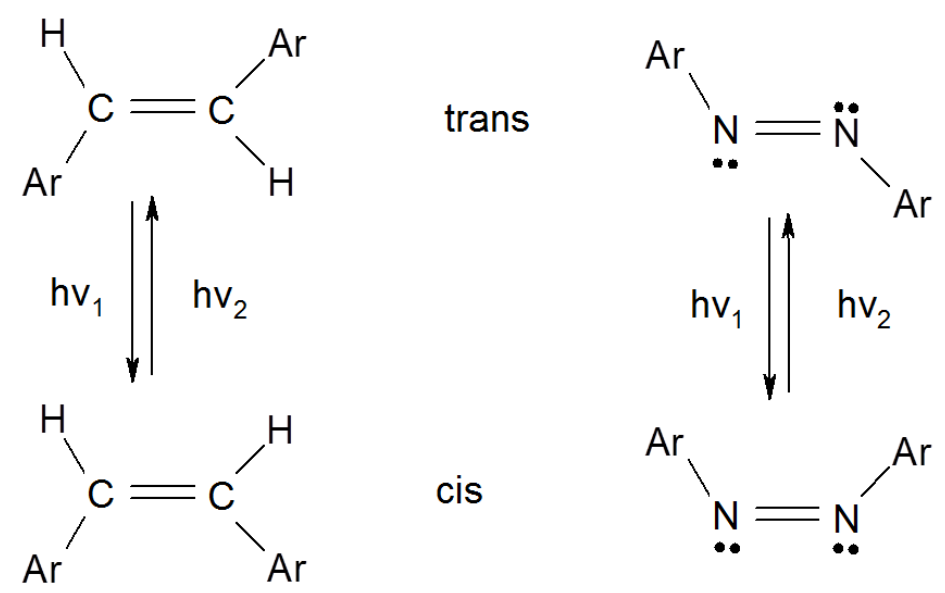

Isomerization changes the mesogenic properties of molecules; -cis form is often non mesogenic or its clearing point is low. For azo compounds, a colour appears. Two ring compounds with $\mathrm{a}-\mathrm{HC}=\mathrm{CH}-$ bridge (stilbene derivatives) remain colorless.

In oligophenylene derivatives, only high-ordered smectic phases are observed, while for compounds with a triple bond or double bonds, a nematic phase is often observed for short alkyl and alkoxy chains. The compounds with alkyl or alkoxy chains, for which the core does not consist of any heteroaromatic rings, are unpolar $(\mu \approx 0)$ and their dielectric anisotropy is small, or even, equals zero $\left(\Delta \varepsilon=\varepsilon_{\|}-\varepsilon_{\perp} \sim 0\right)$. Such molecules cannot be reoriented by an electric field. Further functionalization of molecules by introduction of a polar group with a permanent dipole moment in a lateral position and/or to one side of a terminal position is necessary. The electro-negative atom such as $\mathrm{F}$ or $\mathrm{Cl}$ or a strong electron withdrawing polar group from the following: $\mathrm{CN}, \mathrm{NCS}, \mathrm{CF}_{3}, \mathrm{OCF}_{3}$ are applied. Placement of such groups in the lateral position generates negative dielectric anisotropy; this arrangement leads to the total or partial compensation of their parallel component of dipole moment $\mu_{\|}$. For instance, it is observed for 2,3-substitution, see Figure 5, while 3,4-substitution and similar ones strengthens the $\mu_{\|}$ component of the dipole moment creating molecules with positive dielectric anisotropy. 
Figure 5. Benzene ring with two polar groups in position 3,4-(a) or 2,3-(b) and its resultant dipole moment $\mu$ and $\mu_{\|}$and $\mu_{\perp}$ components with its influence on the dielectric anisotropy of molecule $\mu=\sqrt{\mu_{1}^{2}+\mu_{2}^{2}+2 \mu_{1} \mu_{2} \cos \phi}$.

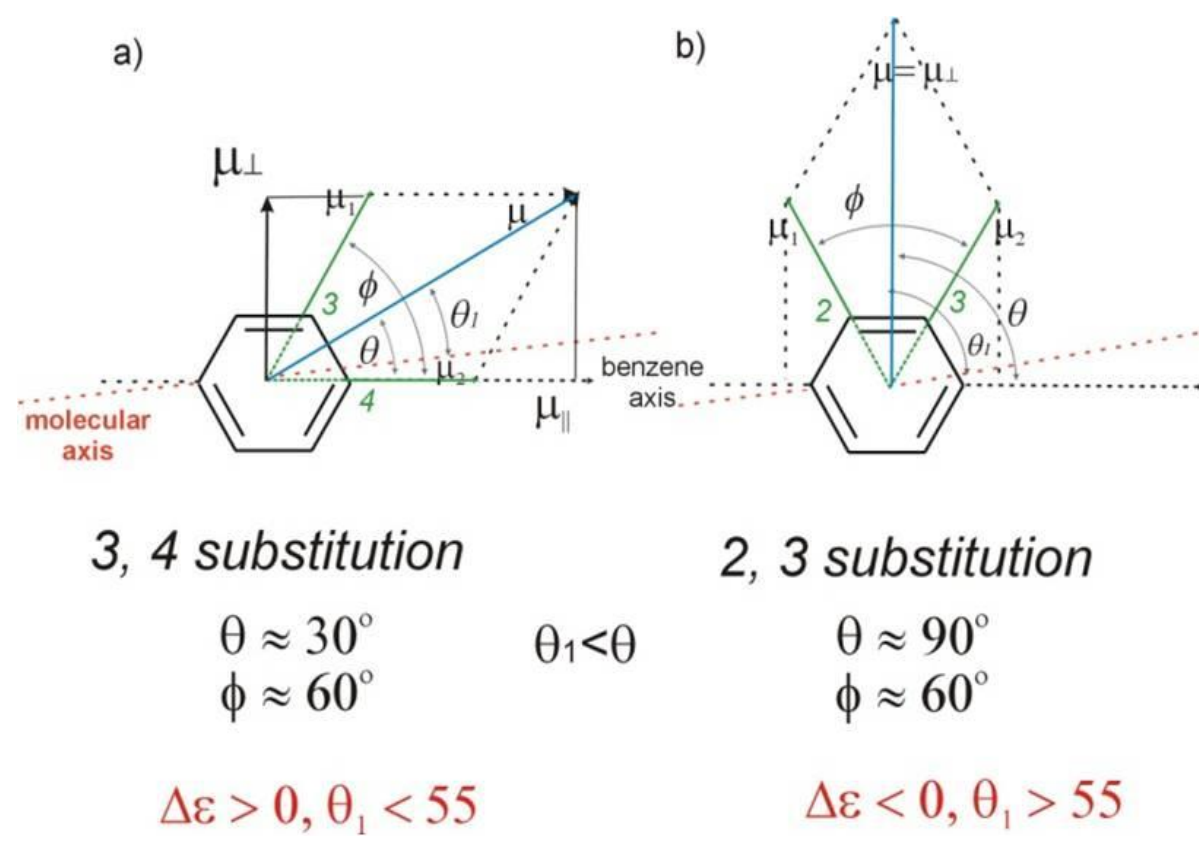

In most cases, fluorine atoms are usually utilized as lateral substituents because their small radius does not involve a large increase in viscosity, which is observed for a more bulky group [66]. The exchange of $\mathrm{F}$ atom into a $\mathrm{CF}_{3}$ or $\mathrm{CN}$ group significantly increases dielectric negative anisotropy, but simultaneously, it may also increase viscosity to an unwanted level [66]. The presence of lateral substituents in adjacent rings, especially in their close neighborhood, causes the twisting of rings, see Figure 6. This perturbs the $\pi$ electron conjugation among the core, causing the birefringence to fall. This particularly concerns the tetrafluoro-substituted terphenyl molecule for which minimum potential torsion energy can be obtained and the fluorine-substituted rings are twisted to about 60-120 deg., Figure 6a.

Figure $6 \mathrm{~b}$ presents the analogue molecule with $-\mathrm{C} \equiv \mathrm{C}$ - bond (phenyltolane derivative) in which the configuration with the lowest potential energy is flat. This molecule finds the lowest potential energy when the rings are in the same plane. The conjugation is not diminished even when the rings are twisted because the two $\pi$ electron pairs of triple bond are perpendicular to each other. The minimum of potential torsion energy is observed for the non-twisted structure and it increases only a little during twisting. A strong interaction between a lone electron pair on the fluorine atom and the $\pi$ electrons of the triple bond exists; see resonance structures given in Figure 7.

This conjugation and polarization is also strong because the lone electron pair of fluorine atom may hinder the rings rotation via resonance structure. It was experimentally confirmed that the dipole moment of molecules with a fluorine atom or fluorine atoms near the triple bond is smaller than for those molecules with fluorines in further positions among the core. 
Figure 6. Change of potential energy of molecules upon twisting the angle between neighbor benzene rings in (a) 2,3,2',3'-tetrafluoro-4,4'-dipropylterphenyl; (b) in 2,3,2',3'-tetrafluoro-4-propyl-4'-(4-propylphenyl)tolane.

a).
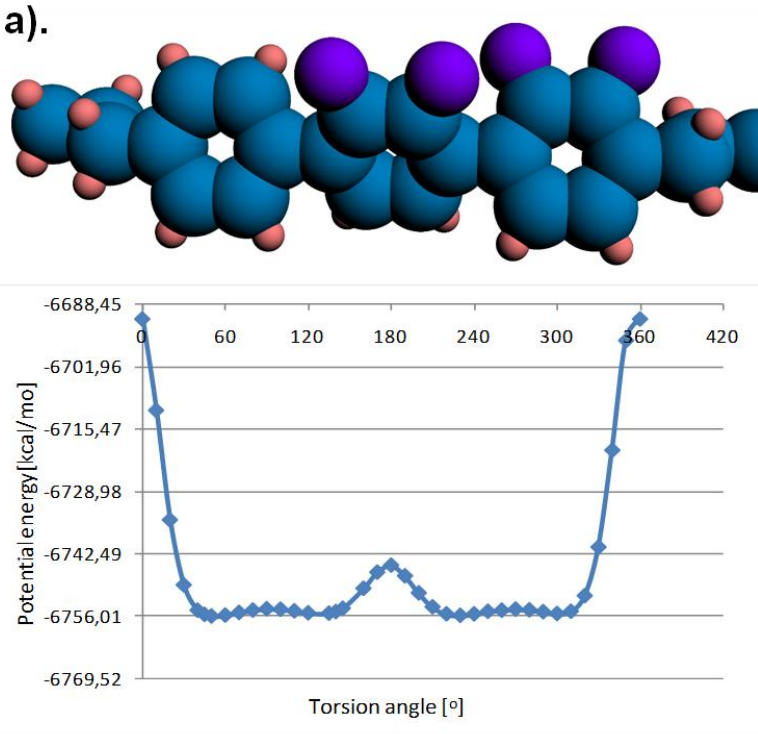
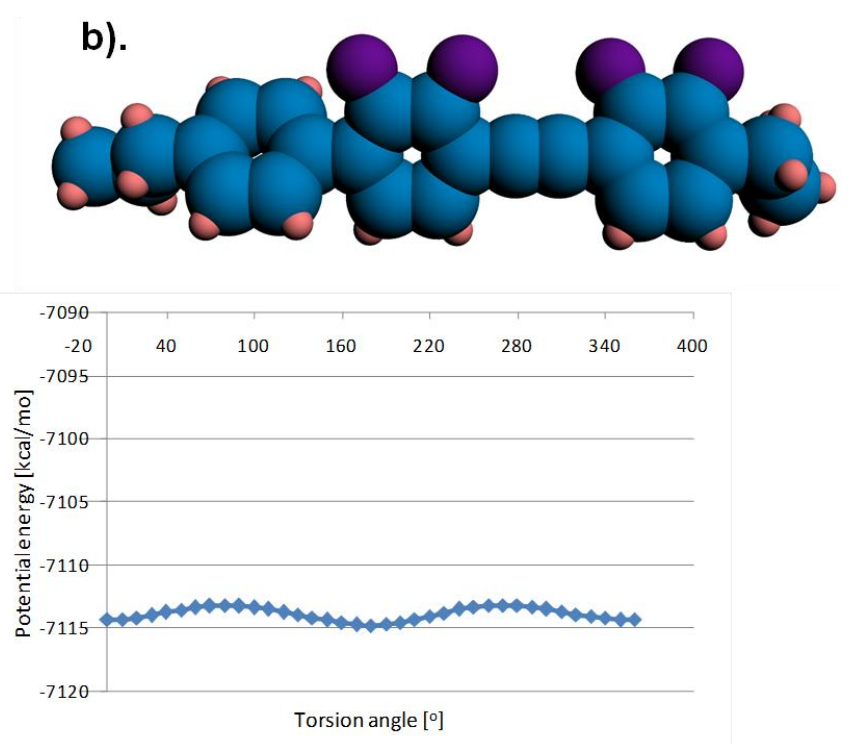

Figure 7. A resonance structure in fluorinated tolane, which flattens the molecule.
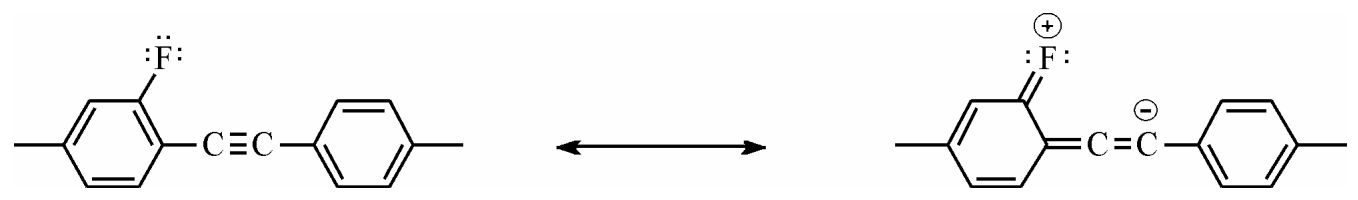

The presence of lateral substituents very often decreases melting points and enhances the nematic range. It is a very effective way to limit the presence of smectic phases in mesogenic rod-like molecules. The placement of a polar group in a terminal position of molecule modifies its dielectric anisotropy, birefringence, elastic constants, viscosity and clearing point, as described in Figure 8.

Figure 8. Functionalization of molecules by introducing a polar group: $\mathrm{F}$ or $\mathrm{Cl}, \mathrm{CN}, \mathrm{NCS}$, $\mathrm{CF}_{3}, \mathrm{OCF}_{3}$ in the terminal position $(\Delta \varepsilon>0)$. The direction of observed changes of properties is given by inequality signs. Dielectric anisotropy $(\Delta \varepsilon)$, birefringence $(\Delta n)$, clearing temperature $\left(T_{N-I}\right)$, viscosity $(v$ or $\eta)$ and elastic constants $\left(k_{i i}\right)$ decrease from left to right.

$$
\begin{aligned}
& \Delta \varepsilon \quad \mathrm{CN}>\mathrm{NCS}>\mathrm{CF}_{3}>\mathrm{OCF}_{3}>\mathrm{Cl}>\mathrm{F} \\
& \begin{array}{lllllll}
\mu & 4.05 & 3.4 & 2.54 & 2.36 & 1.59 & 1.47
\end{array} \\
& \Delta \mathrm{n} \quad \mathrm{NCS}>\mathrm{Cl}>\mathrm{CN}>\mathrm{F}>\mathrm{OCF}_{3}>\mathrm{CF}_{3} \\
& \mathrm{~T}_{\mathrm{N}-\mathrm{I}} \quad \mathrm{CN} \approx \mathrm{NCS}>\mathrm{CF}_{3}, \mathrm{OCF}_{3}, \mathrm{~F} \\
& v(\eta) \quad \mathrm{CN}>>\mathrm{CF}_{3}>\mathrm{OCF}_{3}>\mathrm{NCS}>\mathrm{F} \\
& \mathrm{k}_{\mathrm{ii}} \quad \mathrm{CN} \sim \mathrm{NCS}>\mathrm{Cl}>\mathrm{OCF}_{3}>\mathrm{CF}_{3}>\mathrm{F}
\end{aligned}
$$


Molecules with a CN or NCS terminal group exhibit the highest dielectric anisotropy; however, those with a $\mathrm{CN}$ group have much higher viscosity because their molecules exist in dimeric form as the most stable body. Dimers with the length L, which is 1.4 times larger than single molecule length 1 , can be noticed in small angle diffraction pattern measurements [67,68], see Figure 9.

Figure 9. Model of $5 \mathrm{CB}$ dimer. $\mathrm{L} / \mathrm{l} \approx 1.4$. $\mathrm{L}$-length of dimer, 1 -length of molecule.

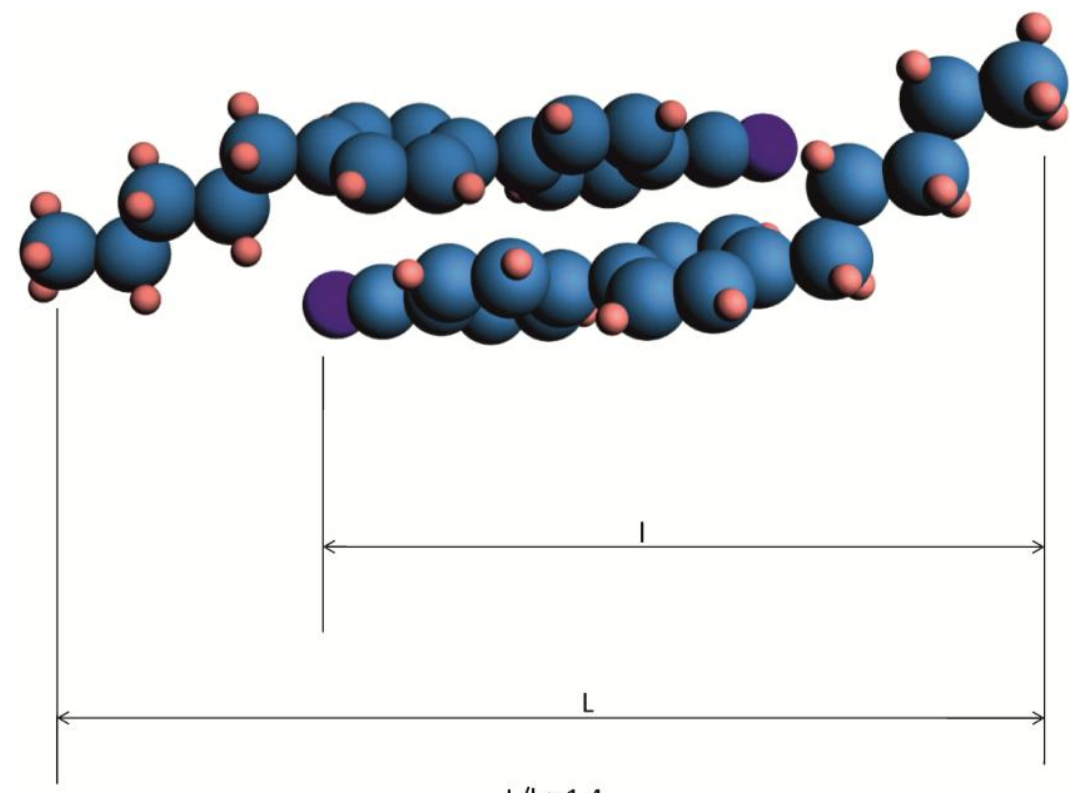

$\mathrm{L} / \mathrm{I} \approx 1.4$

The molecules there are antiparallely correlated. The drop in molecular polarity and increase in alkyl chain length influences the level of association, leading often to the formation of a smectic $A_{d}$ phase with a partial bilayer structure. The presence of other lateral substituent, especially next to the cyano group, interrupts the dimerization, and an increase of static electric permittivity is observed [69]. In the compound with the NCS terminal group, the associates with apparent length $\mathrm{L} \approx 1.2 \mathrm{l}$ are also seen in the nematic phase [70], but in a small concentration. It was observed the monolayer smectic $\mathrm{A}_{1}$ phase, for which layer expands with an increase in the chain length.

Molecules with a NCS group characterize the highest birefringence. The input of NCS group to $\Delta n$ increase is of about 0.07 while input of $\mathrm{CN}$ is rather neutral, and $\mathrm{F}$ atom and $\mathrm{OCF}_{3}$ and $\mathrm{CF}_{3}$ groups decrease $\Delta n$ values. The fluorine atom as the terminal substituent helps to reduce the viscosity, but in some cases, such compounds possess high melting points and smectic phases are often present.

\section{Review of Experimental Results}

The mesogenic and physical properties of two, three and four-ring aromatic compounds with the rings connected directly or via carbon-carbon triple bond will be reviewed to show structural correlations. We are reviewing the compounds with positive dielectric anisotropy (terminated with NCS or CN groups or F atom) and pay special attention to the isothiocyanato compounds as being one of the most important for formulation of large birefringence LC mixtures. These compounds have also been the object of our studies for many years. The compounds with negative dielectric anisotropy will be considered in the separate elaborations. The properties of many of them were also the subject of 
recent work presented by Hird [71]. Homologous members with five carbon atoms in terminal chain $\left(\mathrm{C}_{5} \mathrm{H}_{11}\right)$ or $\mathrm{C}_{4} \mathrm{H}_{9} \mathrm{O}$ including an oxygen atom were taken under consideration for the comparison of the properties of different liquid crystal families. They are thought to be the most representative ones. The compounds with index $n=5$ in the chain are marked only by a number $(\mathbf{1} \ldots \mathbf{1 0 1})$ while other homologous members are marked by adding the letter $\mathrm{a}, \mathrm{b}, \mathrm{c}, \mathrm{d}$, e and $\mathrm{f}$ for $n=1,2,3,4,6$ and 7 , respectively; for example, compound $\mathbf{1 0}$ with the ethyl chain is marked 10b. The compounds with chains $\left(\mathrm{H}_{2 n+1} \mathrm{C}_{n}-\right.$ and $-\mathrm{C}_{m} \mathrm{H}_{2 m+1}$ or $\mathrm{H}_{2 n+l} \mathrm{C}_{n} \mathrm{O}$ - and $\left.-\mathrm{OC}_{m} \mathrm{H}_{2 m+1}\right)$ are marked as 10.n.m (10.1.2 for the methyl and ethyl group or the methoxy and ethoxy group, respectively).

\subsection{Two-Ring Compounds}

The characteristic examples of two-ring compounds with biphenyl core and its heterocyclic analogues are given in Table 1.

Although they do not yet possess very large $\Delta n$, they are very important as necessary components of nematic mixtures. We have also been provided with more information about the properties of these compounds than what is available for multi-ring compounds. Among laterally unsubstituted alkylbiphenyl derivatives, only compound $\mathbf{3}$ terminated with the cyano group is the enantiotropic low-melting nematogen. Also, alkoxy analogue $\mathbf{4 d}$ and pyrimidine analogue $\mathbf{7}$ are nematic compounds, but their melting points are much higher and the nematic phase is monotropic only (observed during cooling below melting). The presence of a heteroatom inside the chain (oxygen) or nitrogen inside the ring increases the clearing point, but simultaneously, strongly increases viscosity (compound $\mathbf{4 d}$ has $\gamma=370 \mathrm{mPa} \cdot \mathrm{s}$ [72], over three times higher than what compound $\mathbf{3}$ has). The birefringence increase is also noticeable but it is rather small. In the homologous series $\mathbf{3}$ and $\mathbf{4 a}$, smectic $\mathrm{A}_{d}$ phase appears for longer chain $(n \geq 8)[73,74]$.

For unsubstituted biphenyl isothiocyanate (compound 1) as well pyrimidine and tiophene analogues (compounds 6 and 9d), only smectic phases are observed in all ranges of mesophase (a higher ordered smectic $\mathrm{E}$ phase in compound $\mathbf{1}$, a smectic $\mathrm{A}_{1}$ phase in compound $\mathbf{6}$ and a smectic $\mathrm{B}$ phase in compound 9d). Only smectic phase $\mathrm{E}$ is observed for homologous series $\mathbf{1}$ for alkyl $n=2-10$ [75]. Also, fluoro terminated compound 5 is a smectic B. Virtual $\mathrm{N}-\mathrm{I}$ transition temperatures (hypothetical $N-I$ transition if they are nematics) of compounds $\mathbf{1}, \mathbf{5}$ and $9 \mathrm{~d}$ are $31{ }^{\circ} \mathrm{C},-28.5{ }^{\circ} \mathrm{C}$ and $26{ }^{\circ} \mathrm{C}$, respectively, estimated from the properties of nematic solution.

The compound $\mathbf{1}$ has the highest birefringence, even a little higher than compounds 9d with an easily polarized thiophene ring. Seed et al. [48,72] gives the values 0.33 and 0.32 for compounds 1 and 9d, respectively, at $25^{\circ} \mathrm{C}$, while for reduced temperatures, $T / T_{N-I}=0.7815, \Delta n=0.41$ and 0.38 . The compound $\mathbf{1}$ has a higher order parameter because its molecules are more linear than for 9d, wherein the thiophenyl ring is not coaxial with the benzene ring. Their value is higher than that obtained by extrapolation from the mixture with compound 8e. They used cyano mixture E7. It is known that in mixtures consisted of cyano and isothiocyanato compounds, $\varepsilon_{\|}$and $\Delta \varepsilon$ increase because the dimerization process is reduced [76]; therefore, the E7 mixture is not appropriate for estimation of optical properties of isothiocyanato compounds. 
Table 1. Properties of biphenyl derivatives and their analogues at temperatures $22-25{ }^{\circ} \mathrm{C}$, where $\eta$ and $\gamma$ represents flow and rotational viscosity, respectively.

\begin{tabular}{|c|c|c|c|c|c|c|c|c|c|c|c|c|c|}
\hline No. & $\begin{array}{c}\Delta H_{m}{ }^{0} \\
{[\mathrm{~kJ} / \mathbf{m o l}]}\end{array}$ & Formula & $\mathrm{Cr}$ & SmE & SmB & $\mathrm{SmA}_{1}$ & $\mathbf{N}$ & Iso & Ref. & $\Delta n$ & $\Delta \varepsilon$ & $\left.\begin{array}{c}\eta \\
{[\mathrm{mPa} \cdot \mathrm{s}]}\end{array}\right]$ & $\begin{array}{c}\gamma \\
{[\mathrm{mPa} \cdot \mathrm{s}]}\end{array}$ \\
\hline 1 & 11.6 & & * 53.1 & $* 73.6$ & - & - & $(* 31.0)^{+}$ & $*$ & {$[75,77]$} & $0.26^{+} ; 0.33^{++}$ & & 15.6 & \\
\hline 2 & 16.5 & & $* 29.1$ & - & - & - & $(* 19.8)$ & $*$ & [78] & $0.25^{+}$ & & & \\
\hline $2 \mathrm{f}$ & 25.7 & & $* 25.8$ & - & - & - & * 29.7 & $*$ & [78] & 0.20 & 9.5 & 15.2 & \\
\hline 3 & 17.2 & & $* 23.2$ & - & - & - & $* 37.2$ & $*$ & {$[73,74]$} & 0.19 & 16.1 & 24 & 102 \\
\hline $4 d$ & 23.2 & & $* 78.0$ & - & - & - & $(* 75.5)$ & $*$ & {$[73,74]$} & & 28.7 & & 370 \\
\hline 5 & 23.3 & & $* 41.4$ & - & $(* 33.6)$ & - & $(*-28.5)^{+}$ & $*$ & [79] & $0.08^{+}$ & & $4^{+}$ & \\
\hline 6 & & & $* 46.0$ & - & - & $* 85.5$ & - & $*$ & {$[80,81]$} & 0.193 & 24.2 & & 102 \\
\hline 7 & & & $* 71.0$ & - & - & - & $(* 52)$ & $*$ & [82] & 0.22 & 34.0 & 55 & 200 \\
\hline 8 & $\begin{array}{l}30.7 \\
13.6^{* * * *}\end{array}$ & & $\begin{array}{c}* 67.5 \\
* 36.0^{+++}\end{array}$ & - & - & - & $(* 49.5)$ & $*$ & {$[83,84]$} & 0.19 & 10.8 & 12 & \\
\hline $8 \mathbf{e}$ & 26.8 & & $* 12.5$ & - & - & - & $* 43.0$ & $*$ & {$[83,84]$} & 0.15 & 8.0 & 13.3 & 83.0 \\
\hline 9d & & & $* 81.2$ & - & $* 84.7$ & - & $(* 26.0)^{++}$ & * & {$[48]$} & $0.32^{++}$ & & & \\
\hline
\end{tabular}


Substitution of compound 1 with one fluorine atom in position 3 (the closest to the isothiocyanato group) transforms this compound into nematic compound 2 with a lower clearing point $\left(19.8{ }^{\circ} \mathrm{C}\right)$ than for cyano compound $3\left(37.2^{\circ} \mathrm{C}\right)$, simultaneously destabilizing smectic E phase. Substitution in the position 2 gives the compound with virtual $N-I$ transition at temperature $-15.4{ }^{\circ} \mathrm{C}$ [85]. The compound 2 exhibits much higher birefringence and lower viscosity than cyano compound $\mathbf{3}$, so it acts as a better component for manufacturing a moderately birefringence mixture than cyano compound $\mathbf{3}$. Also, the transformation of the left benzene ring in the isothiocyanato biphenyl molecule into a cyclohexane unit totally depresses the smectic phase. The compound $\mathbf{8}$ is a monotropic nematic with a high enough melting point and clearing point, but it also has other polymorphic crystal forms that arise during crystallization from its nematic phase, which melts only at $30{ }^{\circ} \mathrm{C}$. On the contrary, the next homologue of this series (compound 8e, $n=6$ ) has a very low melting point - only $12.5^{\circ} \mathrm{C}$ - one of the lowest among polar compounds. Its clearing point is higher than cyano compound $\mathbf{3 e}$. In the family of compound 8, a smectic phase does not appear in analogue $n=12$ [69]. This compound also has very low shear and rotational viscosities. The compound $8 \mathbf{e}$ has high $k_{33}$ and $k_{11}$ values [80,81] but its ratio $k_{33} / k_{11}$ is lower than observed for cyano compound $\mathbf{5}$ and other cyano compounds. Especially, a low $k_{33} / k_{11}$ is observed for isothiocyanato pyrimidine $\mathbf{6}, k_{33} / k_{11} \approx 0.5$, see data in Table 2 .

Table 2. Comparison of elastic constants $\left[10^{-12} \mathrm{~N}\right]$ for cyano- and isothiocyanato compounds at temperature $T_{N-I} T=10$ [80].

\begin{tabular}{ccccc}
\hline Compound No. & $\boldsymbol{k}_{\mathbf{1 1}}$ & $\boldsymbol{k}_{\mathbf{2 2}}$ & $\boldsymbol{k}_{\mathbf{3 3}}$ & $\boldsymbol{k}_{\mathbf{3 3}} / \boldsymbol{k}_{\mathbf{1 1}}$ \\
\hline $\mathbf{3}$ & 6.7 & 3.6 & 9.1 & 1.23 \\
$\mathbf{4 d}$ & - & - & - & 1.24 \\
$\mathbf{6}$ & 5.04 & 3.19 & 4.61 & 0.7 \\
$\mathbf{8 e}$ & 8.57 & 3.70 & 9.51 & 1.11 \\
$\mathbf{7}$ & 7.0 & 3.9 & 8.0 & 1.16 \\
\hline
\end{tabular}

The values of elastic constants in isothiocyanates as well as in other compounds may be shifted to the higher level (more than two times) by introducing a double bond to the chain $[80,81]$. The value of ratio $k_{33} / k_{11}$ strongly depends on the distance of a double bond from the rigid core of a molecule. For example, among the family of compound $\mathbf{8}$, with a double bond in the alkyl chain, the ratio $k_{33} / k_{11}$ changes from 1.10 to 2.00 upon a distance of $-\mathrm{CH}=\mathrm{CH}-$ group from the rigid core increases [80]. In the case of cyano compounds, the observed difference is much larger; also, the position of the double bond in the terminal chain has much influence on the viscosity [80,81].

The compounds with an alkylsulphanyl and an alkylselanyl chain were prepared at Hull University $[48,72,86]$ in order to increase polarizability and birefringence. The replacement of the a butoxy chain in compound 9d into butyl sulphanyl $\left(\mathrm{H}_{9} \mathrm{C}_{4} \mathrm{~S}-\right)$ lead to a small increase in both $n_{\mathrm{e}}$ and $n_{\mathrm{o}}$ and $\Delta n$. The increase of $\mathrm{n}_{\mathrm{o}}$ is explained by the increase in the molecular breadth, while the increase of $n_{\mathrm{e}}$ is explained by the presence of a much more polarizable sulfur atom which is conjugated to the aromatic core. The increase of the order parameter and birefringence for compounds with a butylselanyl $\left(\mathrm{H}_{9} \mathrm{C}_{4} \mathrm{Se}-\right)$ chain instead of a butyl sulphanyl one was also observed [48].

A low viscosity of fluorine was substituted in compound $\mathbf{2}$ and cyclohexane derivative 8 results from its monomeric character. In the nematic phase of compound $\mathbf{8 e}$, X-ray diffraction pattern shows a 
small concentration of bodies with apparent length L/l of 1.21 [70], while for CN compounds, high concentration of dimer with $\mathrm{L} / \mathrm{l} \approx 1.4$ is observed [87]. Substitution of compound 3 in the position close to the cyano group results in a strong increase in electric permittivity [69], which tells us that dimerization disappears ( $\mathrm{L}$ is the length of aggregate and 1 is the single molecule length).

NCS group is coplanar with benzene ring plane and lies almost coaxially to it, see Figure 10. From the monocrystal reflection investigations, the tilt values were obtained between the axis $\mathrm{C}-\mathrm{N}-\mathrm{C}$ bond $169.3{ }^{\circ} \mathrm{C}$ and $\mathrm{N}-\mathrm{C}-\mathrm{S}$ bond $179.9{ }^{\circ} \mathrm{C}$, respectively [88,89]. The length of the bond between benzene ring and $\mathrm{N}$ atom is $1.395 \AA$, which is very close for a $\mathrm{C}-\mathrm{C}$ standard aromatic bond. Resonance structures lead to coplanarity of the NCS group with benzene rings and average the $\mathrm{C}-\mathrm{N}$ bond to the characteristic length for an aromatic bond $(\mathrm{C}-\mathrm{C}, 1.389 \AA$ ), while the length of $\mathrm{N}-\mathrm{C}$ bond is very similar to the triple bond length $(\mathrm{C} \equiv \mathrm{C}, 0.121 \AA)$.

Figure 10. Resonance structures and geometry of NCS group bonded directly to the benzene ring.

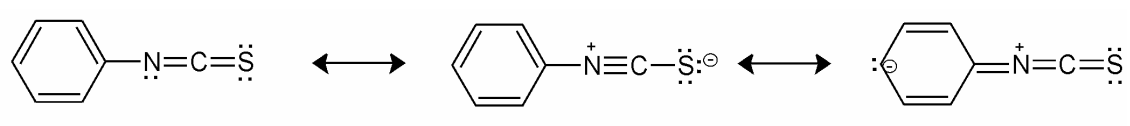

A

B

C

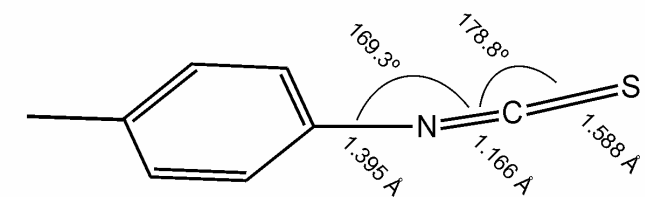

For the phenyl NCS unit, the following resonance structures (Figure 10) are considered [90], which are responsible for NCS conjugation with the benzene ring and are lying in the benzene plane. Laterally unsubstituted, two-ring alkyltolanes exhibit similar mesogenic properties to that observed in biphenyl derivatives, but the melting and clearing points are higher, see Table 3.

Table 3. Phase transition temperatures $\left[{ }^{\circ} \mathrm{C}\right]$, melting enthalpies $[\mathrm{kJ} / \mathrm{mol}]$ and birefringence of alkyltolanes.

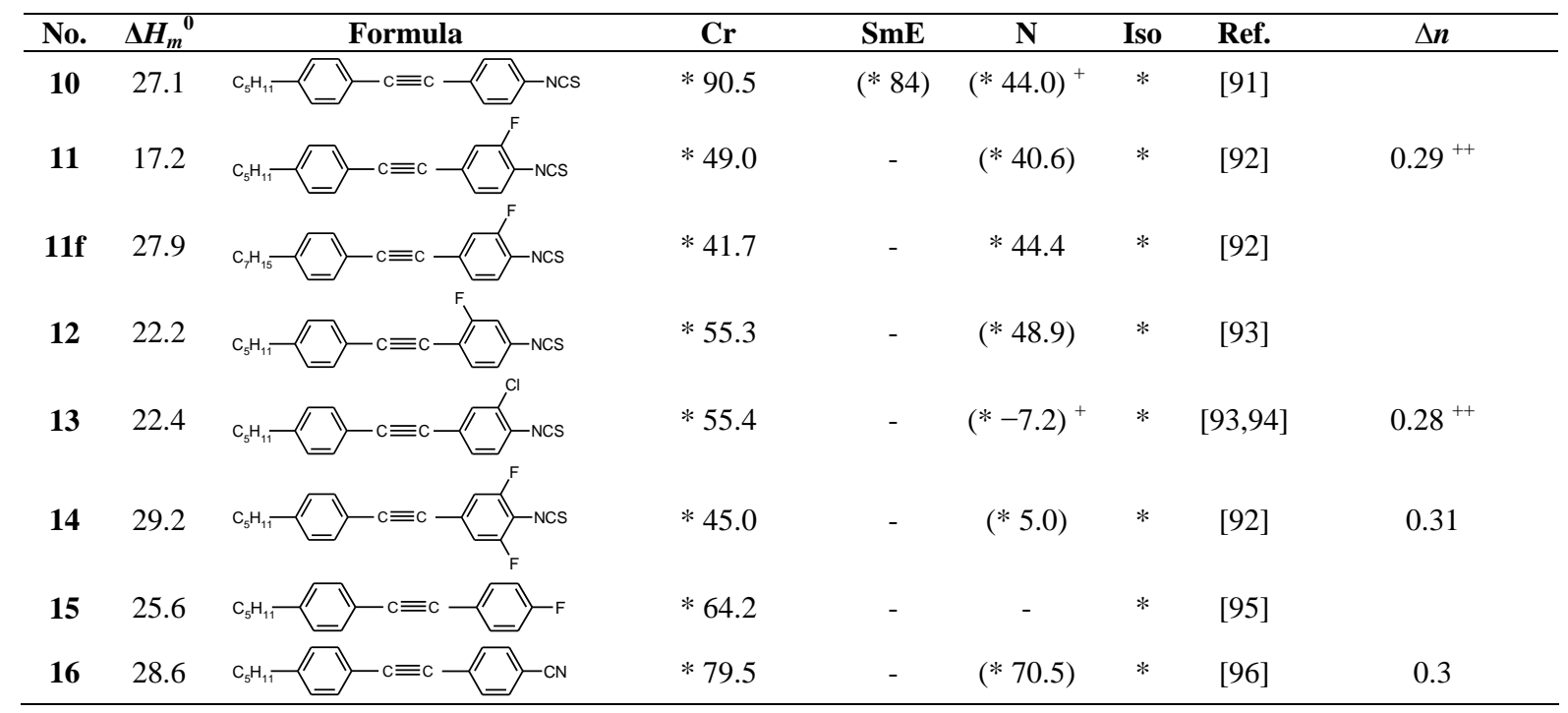

$\overline{{ }^{+}}$virtual N-I transition temperature and $\Delta n$ estimated from solution in compound $\mathbf{8 e} ;{ }^{++} \Delta n$ given at $T-T_{N-I}=-10$. 
In isothiocyanato alkyltolanes (compound 10), only smectic $\mathrm{E}$ is observed, but its chain contains an even number of carbon atoms $(n=4$ and $n=6)$ and at a lower temperature, smectic $\mathrm{K}$ phase is observed [97]. The temperature of virtual $N-I$ transition is $44.0^{\circ} \mathrm{C}$. Fluorine analogue (compound 15) is not mesogenic, while cyano terminated compound $\mathbf{1 6}$ with a monotropic nematic with a clearing point at $70.5^{\circ} \mathrm{C}$. Also, the introduction here of one fluorine atom into the benzene ring (compound 11) completely destroys the smectic E phase. A monotropic nematic phase appears for pentyl member (compound 11) while heptyl member (compound 11f) is already enantiotropic nematic. This is the general relation for tolane compounds, also observed among three ring compounds. Substitution of benzene ring in tolane core by a chlorine atom (compound 13) or by two fluorine atoms (compound 14) strongly depresses the clearing point. Two fluorine atoms decrease the clearing point with less than one chlorine atom. A three-component eutectic mixture, consisting of 11c, 11 and 11f, had viscosity $\left(\eta=19 \mathrm{mPa} \cdot \mathrm{s}\right.$ and $\gamma=88 \mathrm{mPa} \cdot \mathrm{s}, \Delta n=0.34$ at $589 \mathrm{~nm}$ and $20{ }^{\circ} \mathrm{C}$, melting point $\left(-2{ }^{\circ} \mathrm{C}\right)$ and clearing point $40.1{ }^{\circ} \mathrm{C}$ ) [92]. Higher clearing point can be observed for isomeric compound 12, wherein fluorine is close to the triple bond. Alkoxy tolanes have higher clearing points than alkyl tolanes, see Table 4.

Table 4. Phase transition temperatures $\left[{ }^{\circ} \mathrm{C}\right]$, melting enthalpies $[\mathrm{kJ} / \mathrm{mol}]$ and birefringence of alkoxytolanes and alkylsulphanyl tolanes.

\begin{tabular}{|c|c|c|c|c|c|c|c|c|c|}
\hline No. & $\Delta H_{m}{ }^{0}$ & Formula & $\mathrm{Cr}$ & SmE & SmB & $\mathbf{N}$ & Iso & Ref & $\Delta n$ \\
\hline $17 d$ & 25.6 & & * 112.7 & $(* 112.0)$ & - & $* 116$ & $*$ & [91] & 0.44 \\
\hline $18 d$ & 18.9 & & $* 108.0$ & - & - & $* 111$ & $*$ & {$[98,99]$} & \\
\hline 19d & & & $* 84.8$ & - & * 85.4 & $(* 65)^{+}$ & $*$ & [72] & 0.49 \\
\hline 20d & & & * 83.3 & - & - & * 53.3 & $*$ & [72] & 0.29 \\
\hline 21d & 35.6 & & * 96.7 & - & - & $(* 89.9)$ & $*$ & [91] & 0.31 \\
\hline 22d & 24.2 & & $* 70.3$ & - & - & * 94.4 & $*$ & [93] & 0.30 \\
\hline 23d & 27.6 & & $* 81.6$ & - & - & $(* 31.0)$ & $*$ & [93] & 0.26 \\
\hline $24 d$ & 30.1 & & * 73.6 & - & - & $(* 48.4)$ & $*$ & [85] & 0.25 \\
\hline $25 \mathrm{~d}$ & 24.2 & & $* 64.2$ & - & - & * 71.6 & $*$ & [91] & 0.29 \\
\hline $26 d$ & 27.2 & & $* 68.2$ & - & - & $(* 48.5)$ & $*$ & [93] & 0.28 \\
\hline $27 \mathrm{~d}$ & 27.8 & & $* 71.0$ & - & - & $(* 62.0)$ & $*$ & [92] & \\
\hline
\end{tabular}

${ }^{+}$virtual $N-I$ temperature estimated from E7 solution [72].

Unsubstituted 4'-butoxy-4-isothiocyanatotolane (compound 17d) has a high melting point and clearing point; similar behavior is observed for the cyano analogues $\mathbf{1 8 d}$. However, the monotropic smectic E phase and enantiotropic nematic phase is observed for 17d, which appears in a narrow temperature range. Analogous alkylsulphanyl derivative 19d possess only smectic B phase, but its melting and clearing temperatures are lower than these observed in alkoxy derivative. Virtual $N-I$ transition is lower by about 50 Kelvins. Cyano derivative 20d is a monotropic nematic compound with 
low clearing point. The exchange of alkoxy chain into analogue alkylsulphanyl chain involves a significant decrease in clearing points [48].

Seed et al. [48] found for compound 19d and 20d $\Delta n$ values 0.49 and 0.29 , respectively ( 0.5 and 0.34 at $\left.T / T_{N-I}=0.7815\right)$. It seems that the first value is too large, probably because of the host used, which was an E7 mixture.

The placement of a lateral substituent such as fluorine, chlorine or methyl group totally removes the smectic phases in alkoxytolanes [93,94], but simultaneously, the clearing points decrease as follows: $\mathrm{Cl}<\mathrm{CH}_{3}<\mathrm{F}$, comparing $T_{N-I}$ temperatures of compounds: 23d, 24d, 21d. It is a common relation found also in multi-ring compounds. The tolanes with alkoxy terminal chain generally have higher clearing points, higher viscosity and very often, higher melting points than alkyl terminated derivatives. Due to their high clearing points, they may be used as the main components of medium birefringence mixtures $(\Delta n \sim 0.3)$ without or only with a small number of three-ring compounds. Another general rule validated for tolanes is the following: compounds with fluorine next to the triple bond have higher clearing points than those with the fluorine atom positioned further from the triple bond (compare compounds $22 \mathbf{d}$ and $\mathbf{2 1 d}$ or $\mathbf{2 5 d}$ ). The last compound with fluorine close to the butoxy group has a lower $T_{N-I}$ of 18 Kelvin, but chlorine in this position influences the $T_{N-I}$ in the opposite way, with compound 26d having a higher $T_{N-I}$ than compound 23d. Dielectric anisotropy of tolanes with fluorine in the neighborhood of the triple bond is lower than those with fluor pending in the same directions, but at a long distance from the triple bond [100]. Refractive indices of differently substituted alkyl and alkoxy isothiocyanato tolanes are compared at temperature $T_{N-I} T=10{ }^{\circ} \mathrm{C}$ in Table 5.

Table 5. Birefringence and refractive indices of alkyl and alkoxy isothiocyantotolanes at reduced temperature $T_{N-I}=-10{ }^{\circ} \mathrm{C}$.

\begin{tabular}{cccc}
\hline No. & $\boldsymbol{\Delta n}$ & $\boldsymbol{n}_{\mathbf{0}}$ & $\boldsymbol{n}_{\mathrm{e}}$ \\
\hline 11 & 0.2928 & 1.5674 & 1.8602 \\
13 & 0.2828 & 1.5964 & 1.8792 \\
21d & 0.3121 & 1.5574 & 1.8695 \\
22d & 0.2963 & 1.5615 & 1.8682 \\
23d & 0.2618 & 1.5769 & 1.8392 \\
24d & 0.2508 & 1.5734 & 1.8242 \\
25d & 0.2890 & 1.5720 & 1.8582 \\
$26 \mathrm{~d}$ & 0.2768 & 1.5974 & 1.8742 \\
\hline
\end{tabular}

Chloro-substituted compounds $\mathbf{2 3 d}$ and $\mathbf{2 6 d}$ as well as methyl substituted one $\mathbf{2 4 d}$ have lower birefringence than analogous fluorosubstituted compounds $21 \mathbf{d}$ and $\mathbf{2 5 d}$. For the first two compounds, a decrease of $\Delta n$ results from a higher ordinary index $n_{\mathrm{o}}$ (chlorocompounds). The compound $\mathbf{2 4 d}$ has $n_{\mathrm{o}}$ a little higher and $n_{\mathrm{e}}$ little lower.

Bulky substituents make the molecules broader and they become more polarizable in the direction perpendicular to the long axis. The same is observed for sulphanyl derivatives $\mathbf{1 8 d}$ and $\mathbf{1 9 d}$. 


\subsection{Three-Ring Compounds}

\subsubsection{Therphenyl Derivatives}

Tables 6 and 7 present characteristic alkyl terphenyl isothiocyanates, while cyanides and fluorides are listed in Tables 8 and 9 to show the influence of lateral substitution on their mesogenic and physical properties.

Table 6. Phase transitions temperatures $\left[{ }^{\circ} \mathrm{C}\right]$, melting enthalpies $[\mathrm{kJ} / \mathrm{mol}]$, birefringence and bulk viscosity $[\mathrm{mPa} \cdot \mathrm{s}]$ of 4 "-alkyl-4-isothiocyanatoterphenyls.

28 No.

${ }^{+}$calculated from Demus mixture for one concentration; ${ }^{++}$extrapolated from Demus mixture for three concentrations.

Table 7. Influence of alkyl length on phase transition temperatures $\left[{ }^{\circ} \mathrm{C}\right]$ and melting enthalpies [kJ/mol] in homologous series of compounds 34 and 36 [102].

\begin{tabular}{ccccccc}
\hline No. & $\boldsymbol{n}$ & ${\boldsymbol{\Delta \boldsymbol { H } _ { \boldsymbol { m } }}}^{\mathbf{n}}$ & $\mathbf{C r}$ & $\mathbf{S m A}$ & $\mathbf{N}$ & $\mathbf{I s o}$ \\
\hline $\mathbf{3 4}$ & 5 & 23.6 & $* 74.0$ & $* 118.3$ & $* 181.8$ & $*$ \\
$\mathbf{3 4 d}$ & 4 & 27.1 & $* 97.8$ & $* 111.7$ & $* 178.1$ & $*$ \\
$\mathbf{3 4 c}$ & 3 & 31.1 & $* 127.7$ & - & $* 193.0$ & $*$ \\
$\mathbf{3 4 b}$ & 2 & 25.6 & $* 102.3$ & - & $* 180.4$ & $*$ \\
$\mathbf{3 6}$ & 5 & 25.4 & $* 56.3$ & & $* 159.6$ & $*$ \\
$\mathbf{3 6 d}$ & 4 & 16.5 & $* 66.5$ & $* 73.9$ & $* 156.7$ & $*$ \\
$\mathbf{3 6 c}$ & 3 & $22.1 ; 12.3$ & $* 68.8 ; 75.7$ & - & $* 169.1$ & $*$ \\
$\mathbf{3 6 b}$ & 2 & 24.0 & $* 76.7$ & - & $* 160.6$ & $*$ \\
\hline
\end{tabular}

Many mono-, di-, tri- and tetrafluoro-substituted isothiocyanatoterphenyls have been prepared in our laboratory during the last decade [78,101-103]. They were tested as mixture components in cooperation with $\mathrm{Wu}$, S.T. group. 4"-Alkyl-4-cyanoterphenyls were synthesized for the first time in G. Gray's laboratory at the beginning of 1970s [73,74] and their syntheses have been improved up 
until now because they are important components of many commercial mixtures such as E7 or BL037 and BL038. They are also interesting for their flexoelastic property [104].

Monofluorinated isothiocyanatoterphenyl 28 still exhibits a very high melting point and the smectic phase exists up until $195{ }^{\circ} \mathrm{C}$. The high thermal stability of the smectic A phase is also seen for the members with a shorter propyl chain [78]. Its cyclohexyl analogue 29 already has a low melting nematic compound [101]. The shift of the fluorine atom to the central position (compound 30) decreases both the melting point and the stability of smectic A phase.

Placement of two fluors in the lateral position of the molecule involves a further decrease in melting points, which reduces the smectogenity. The ability for destabilizing the smectic A phase is strongly related to the position of its substituents. For double substituted compounds, the following relation is observed: 3,3' (33) $<3,5(\mathbf{3 2})<2^{\prime}, 3^{\prime}(\mathbf{3 4})$.

Generally, for most of the cases, substituents lying on the same side of the molecule less effectively depress the stability of smectic A phase than those lying on opposite side of molecule, except of compound (33). The same is observed for fluorides, comparing compounds $\mathbf{5 6}$ and $\mathbf{5 8}$, see Table 9. For cyanide 47 (2',3'-substitution) (see Table 8$)$, the smectic phase is even induced, however, for other types of substitution, the strong nematic character of compounds is observed. It is a quite different feature than that observed in 4,4"-dialkyl- or 4"-alkyl-4-alkoxylterphenyl derivatives in which $2^{\prime}, 3^{\prime}$-substitution always involves not only significantly decreasing melting points but also significantly depressing smectogenity [71].

Table 8. Phase transitions temperatures $\left[{ }^{\circ} \mathrm{C}\right]$, melting enthalpies $[\mathrm{kJ} / \mathrm{mol}]$, birefringence, bulk viscosity $[\mathrm{mPa} \cdot \mathrm{s}]$ and dielectric anisotropy of alkyl cyanoterphenyls.

\begin{tabular}{|c|c|c|c|c|c|c|c|c|c|c|c|}
\hline No. & $\Delta H_{m}{ }^{0}$ & Formula & $\mathrm{Cr}_{1}$ & $\mathrm{Cr}_{2}$ & SmA & $\mathbf{N}$ & Iso & Ref. & $\Delta n$ & $\Delta \varepsilon$ & $v$ \\
\hline 38 & 25.6 & & * 115 & $* 131$ & - & $* 240$ & $*$ & [74] & $0.3^{+}$ & 16 & 86 \\
\hline 39 & 26.4 & & - & * 131.5 & - & $* 263$ & $*$ & {$[105]$} & & & \\
\hline 40 & 25.1 & & - & * 124 & - & $* 205$ & $*$ & {$[105]$} & & & \\
\hline 41 & & & - & $* 86$ & - & $* 183$ & $*$ & [104] & & 19.6 & \\
\hline 42 & & & - & $* 82$ & - & * 143 & $*$ & [104] & & 17.9 & \\
\hline 43 & & & - & * 104 & - & * 209.4 & $*$ & [85] & & & \\
\hline 44 & & & - & * 97 & - & * 189 & $*$ & [106] & $0.34^{+}$ & 10 & \\
\hline 45 & & & - & $* 82.5$ & - & * 162.3 & $*$ & [85] & & 31 & \\
\hline 46 & & & - & * 103 & - & $* 120$ & $*$ & [104] & & 20.9 & \\
\hline 47 & & & - & * 101 & $* 170$ & $* 175$ & $*$ & [104] & & 17.3 & \\
\hline 48 & & & - & $* 91$ & - & $* 122$ & $*$ & [104] & & & \\
\hline 49 & & & - & $* 27$ & - & $* 45$ & $*$ & [104] & & & \\
\hline
\end{tabular}


Table 9. Phase transitions temperatures $\left[{ }^{\circ} \mathrm{C}\right]$, enthalpies $[\mathrm{kJ} / \mathrm{mol}]$, birefringence, rotational viscosity $[\mathrm{mPa} \cdot \mathrm{s}]$ and dielectric anisotropy of alkyl fluoroterphenyls.

\begin{tabular}{|c|c|c|c|c|c|c|c|c|c|c|}
\hline No. & $\Delta H_{m}{ }^{0}$ & Formula & $\mathrm{Cr}$ & SmA & $\mathbf{N}$ & Iso & Ref. & $\gamma$ & $\Delta n$ & $\Delta \varepsilon$ \\
\hline 50 & & & * 207 & - & - & $*$ & [104] & & & \\
\hline 51 & & & $* 88$ & * 103 & * 160 & $*$ & [107] & & & \\
\hline 52 & & & $* 103.7^{+}$ & * 165 & - & * & [102] & & & \\
\hline 53 & & & $* 72.8$ & $\begin{array}{c}* \\
146.4\end{array}$ & * 151.1 & * & [85] & & & \\
\hline 54 & 18.1 & & $* 55$ & - & * 105.4 & $*$ & {$[1,6]$} & 210 & 0.14 & 6.3 \\
\hline 55 & & & $* 80$ & * 128 & * 147 & $*$ & [104] & & & \\
\hline $56 c$ & & & * 75.4 & $* 78$ & * 82.5 & $*$ & [108] & & 0.22 & \\
\hline $57 c$ & 17.4 & & * 64.7 & - & $*(20.7)^{++}$ & $*$ & [102] & & & \\
\hline 58 & & & * 94 & - & $* 97$ & $*$ & [104] & 168 & 0.22 & 19.2 \\
\hline $59 c$ & 21.0 & & * 62.5 & - & $*(23.0)^{++}$ & $*$ & [108] & & & \\
\hline 60 & & & * 102.6 & - & * 110.9 & $*$ & [102] & & & \\
\hline $61 c$ & & & * 108 & - & $*(-6.1)^{++}$ & $*$ & [3] & 177 & 0.21 & 23.4 \\
\hline
\end{tabular}

Compound 32 and other members of this homologous series show very low melting enthalpy (only about $10.3 \mathrm{~kJ} / \mathrm{mol}$ for the pentyl member), therefore they show excellent miscibility in mixtures. Only a nematic phase is observed for 3,3',5-trisubstituted compound 36, and shorter members of this series also have low melting points, see Table 7. 2',3'3-trisubstituted compound $\mathbf{3 5}$ has less convenient properties, as well as tetrasubstituted compound $\mathbf{3 7}$, wherein the stability of the smectic A phase and the melting point again increase. The comparison of $F o M_{1}$ of terphenyl isothiocyanates having a different number of fluorine atoms and a different alkyl chain length shows that they fall quickly with an increase in fluorine numbers in the lateral position, and increase with the shortening of the alkyl chain length [103]. Difluoro-substituted compounds $\mathbf{3 2}$ and $\mathbf{3 3}$ with the ethyl and propyl chain are the most optimal mixture components because they exhibit the lowest viscosity and the largest birefringence. Often, members with shorter alkyl chain have higher melting points than those with a longer alkyl chain; see compound $\mathbf{3 4}$ in Table 7 as a characteristic example. In some homologous series, for example, in compound 36, the length of the alkyl chain only slightly influences the melting points and melting enthalpy. The short members of such series exhibit also good miscibility in mixtures. Alkyl fluoro-terphenyls (see Table 9) resemble the mesogenic properties of isothiocyanates, but they have much lower clearing points-about 70 Kelvins for mono fluorosubstituted compounds 
and this difference becomes larger for the increase in the amount of lateral substituents (compare compounds 37 and 61). They have also more ability to be smectic mesogens than isothiocyanates (compare compounds 28 and 52). Unsubstituted compound $\mathbf{5 0}$ or monosubstituted compound $\mathbf{5 2}$ have very high melting points and smectic phases are observed in all ranges of the mesophase. Although pyrimidine analogues, compounds $\mathbf{5 1}$ and $\mathbf{5 3}$ are unexpectedly more polar, having lower melting points and lower smectogenity, which makes them interesting mixture components. For terphenyl fluorides, similarly as for terphenyl isothiocyanates, an exchange of the left-side benzene ring for the cyclohexane unit transforms the compounds $\mathbf{5 0}$ and $\mathbf{5 2}$ to low-melting nematic compounds (compare compounds 52 and 54). The latter are often used as the components of blue phase mixtures [109]. 3',3-difluoro-substituted compound 56c is still a smectic A compound with a narrow range nematic phase (a few Kelvins), while substitution in the position 3,5 or $2^{\prime}, 3^{\prime}$ gives nematics. Suppossedly, they could also have smectic phases at lower temperatures, but their high melting points disenable them to have monotropic phases. Trifluoro-substituted compounds in the position $3^{\prime}, 3,5$ or $3^{\prime \prime}, 3^{\prime}, 3$ are low-melting virtual nematics with clearing points only at $\sim 20^{\circ} \mathrm{C}$. Tetrafluoro-substituted compound $\mathbf{6 1}$ is again a high melting mesogen with a very low virtual clearing point $\left(-6{ }^{\circ} \mathrm{C}\right)$. Cyanoterphenyl derivatives have quite different mesogenic properties than fluoro and isothiocyanato derivatives, see Table 8. As far back as unsubstituted compounds such as $4^{\prime \prime}$-pentylcyanoterphenyl $\mathbf{3 8}$ as well as 5-pentyl-2-(4-cyanobiphenyl) pyrimidine $\mathbf{4 0}$ together with its isomeric analogue 38 are nematics with a melting point of about $125{ }^{\circ} \mathrm{C}$, even so, their moderate melting enthalpy often results in their use as mixture components (see for example E7 or BL038 mixtures). Monofluoro-substituted analogue in position 3 (compound 41) as well as in $3^{\prime}$ (compound 42) and difluoro-substituted analogue in position $3^{\prime}, 3$ (compound 45) have the lowest melting points, of about $80{ }^{\circ} \mathrm{C}$. The smectic A phase with high thermal stability is present only in $2^{\prime}, 3^{\prime}$-difluoro substituted compound 47 while $2^{\prime}, 3^{\prime}, 3,5$-tetra-substituted compound 49 has an extremely low melting and clearing point, which makes its properties similar to fluoro analogue 61. Such low transition points may indicate that dimerization in this compound is completely ceased. Isothiocyanatoterphenyls have a birefringence $\Delta n \approx 0.35-0.45$ (at room temperature) while for cyanoterphenyl $\sim 0.3-0.35$ and fluoroterphenyl only $\sim 0.22-0.25$. Bulk viscosity is equal to 30, 90 and 45.8, respectively, and increases with the fluors number in the lateral position.

\subsubsection{Phenyl Tolanes}

A large number of mono-, di-, tri- and tetrafluoro-substituted 4'-(4-alkylphenyl)-4-isothiocyanatotolanes have already been prepared in our laboratory [85,92,93], see Table 10. Individual cyano and fluoro compounds are also known [85].

There are many similarities in the lateral substituents' influence on their ability to form smectic phases and their thermal stability in phenyl tolane and terphenyl families. Also, here the substitution of the central ring next to the triple bond depresses the smectic phase less so than the substitution of the side ring, comparing two substituted compounds 69 and 70 with 66 or 68 . In the last mentioned compound, in which the fluorine atom is positioned as $2^{\prime}$, twisting the left ring depresses the smectic phase more effectively. Among trifluoro-substituted compounds, the nematic phase show only $2^{\prime}, 3,5$-substituted compound 72d and $3^{\prime \prime}, 5^{\prime \prime}, 3^{\prime}$-substituted compound 78. Other substituted analogues such as $3^{\prime}, 3,5$ (compound 73) or $2^{\prime}, 3^{\prime}, 3$ (compound 75) or $2^{\prime}, 3^{\prime}, 2$ (compound 76) have a smectic phase 
up to $135{ }^{\circ} \mathrm{C}$. Also, 2',3',3,5 tetrafluoro-substituted compound 79 has the smectic A phase up to $116.9{ }^{\circ} \mathrm{C}$ showing also a high clearing point. The compounds having fluorine atoms at both sides of ring $\left(3,5\right.$ or $3^{\prime \prime}, 5^{\prime \prime}$ substitution) have the nematic phase in a broader temperature range than those substituted at the same side $\left(3^{\prime}, 3\right.$ or $\left.2^{\prime}, 3^{\prime}\right)$ of the ring, comparing compounds $\mathbf{7 8}$ and $\mathbf{7 2 d}$ with 75 and 76. Also, in the case of phenyl tolanes, the exchange of the left benzene ring into a cyclohexane unit eliminates the smectic phases completely. Compound 67 with a low melting point and broad range of nematic phase arises. The placement of $\mathrm{CH}_{3}$ group near the triple bond in the central benzene ring also totally removes the presence of the smectic phase (see compounds 65 and 71). The clearing point decreases by about 40 Kelvins, compared to fluoro analogues $\mathbf{7 0}$ and $\mathbf{7 3}$. The compound $\mathbf{7 7}$ with triple bond on the left side of the molecule is a low melting nematic and possesses a higher clearing point than its analogue $\mathbf{7 3}$ with triple bond on the right side. Cyano compound $\mathbf{7 8}$ and its analogue $\mathbf{7 7}$ are nematics with a higher melting point.

Table 10. Influence of lateral substitutions on mesogenic properties of alkyl phenyltolanes.

Phase transition temperatures $\left[{ }^{\circ} \mathrm{C}\right]$ and melting enthalpies $[\mathrm{kJ} / \mathrm{mol}]$.

\begin{tabular}{|c|c|c|c|c|c|c|c|c|c|c|}
\hline No. & $\Delta H_{m}{ }^{0}$ & Formula & $\mathrm{Cr}$ & SmE & SmB & SmA & $\mathbf{N}$ & Iso & Ref. & $\Delta n$ \\
\hline 62d & 15.2 & $\mathrm{C}_{4} \mathrm{H}_{9}-\widehat{C}$ & $* 76.0$ & $* 89.0$ & * 103.4 & * 194.6 & $* 247.0$ & $*$ & [93] & \\
\hline 63d & 10.5 & $\mathrm{C}_{4} \mathrm{H}_{9}-\mathrm{C}_{\mathrm{C}}$ & * 52.3 & $* 85.7$ & * 139.3 & * 181.3 & $* 248.5$ & $*$ & [93] & \\
\hline 64d & 23.9 & $\mathrm{C}_{4} \mathrm{H}_{9}-C_{\mathrm{C}}$ & $* 98$ & - & - & * 135 & $* 214$ & $*$ & {$[85]$} & \\
\hline 65 & 22.6 & & $* 108.7$ & - & - & $*$ & * 233.1 & $*$ & {$[85]$} & \\
\hline 66d & 20.1 & $\mathrm{C}_{\mathrm{H}} \mathrm{H}_{-}<\mathrm{C}$ & $* 63.3$ & - & - & $* 105.3$ & * 212.7 & $*$ & {$[92]$} & \\
\hline 66 & 20.1 & & $* 61.4$ & - & $(* 55.2)$ & $* 118.7$ & $* 210.4$ & $*$ & [92] & 0.46 \\
\hline 67 & 23.9 & & $* 50.5$ & - & - & - & * 196.3 & $*$ & {$[85]$} & 0.38 \\
\hline $67 d$ & 26.7 & & $* 75.7$ & - & - & - & $* 213.6$ & $*$ & {$[85]$} & \\
\hline $68 d$ & 24.1 & & $* 60.6$ & - & - & $* 77.6$ & $* 210.2$ & $*$ & {$[85]$} & \\
\hline 68 & 24.5 & & * 68.3 & - & - & $* 88.5$ & * 198.9 & $*$ & {$[85]$} & \\
\hline 69 & 26.5 & & $* 70$ & - & - & * 149.7 & * 231.3 & $*$ & [110] & \\
\hline 70 & 17.5 & & * 55.5 & - & - & * 163.4 & * 232.0 & $*$ & {$[85]$} & \\
\hline 71 & 21.78 & & * 97.3 & - & - & - & * 194.8 & $*$ & {$[85]$} & \\
\hline 72 & 22.0 & & $* 66.7$ & - & - & - & $* 172.5$ & $*$ & [111] & \\
\hline 73 & $11.1 ; 17.6$ & & $\begin{array}{c}* 49.3 \\
55.0\end{array}$ & - & - & $* 130.2$ & * 226.3 & $*$ & {$[85]$} & \\
\hline 74 & 27.2 & $\mathrm{c}_{5} \mathrm{H}_{1}-$ & $* 76.7$ & - & - & - & $* 168.4$ & $*$ & {$[85]$} & \\
\hline 75 & 27.3 & & $* 53.2$ & - & - & $* 133.5$ & * 218.4 & $*$ & [110] & 0.50 \\
\hline 76 & 25.5 & & $* 58$ & - & - & $* 134.7$ & $* 222$ & $*$ & [85] & \\
\hline 77 & 25.6 & $\mathrm{C}_{\mathrm{s}} \mathrm{H}_{1} \mathrm{C}$ & $* 74.5$ & - & - & - & $* 224.3$ & $*$ & [85] & \\
\hline 78 & 26.9 & $\mathrm{c}_{\mathrm{s}+\mathrm{H}_{1}}<\mathrm{C}$ & $* 101.2$ & & & & $* 212.8$ & $*$ & [85] & \\
\hline 79 & 26.7 & $\mathrm{C}_{5} \mathrm{H}_{1}-<$ & $* 46$ & & & * 116.9 & * 202.2 & $*$ & {$[85]$} & \\
\hline 80d & 26.2 & 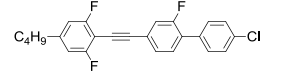 & $* 72.1$ & - & - & - & $* 152.3$ & $*$ & {$[85]$} & \\
\hline
\end{tabular}


The presence of a triple bond effectively increases the clearing points of multifluoro-substituted compounds, maintaining the melting temperature at a moderately high level. The dialkyl analogues of 77 have a melting point at around room temperature [112]. In this series, the lowest melting points are observed for difluoro-substituted compounds such as 81dd, see Table 11. Here, an increase in the number of fluors leads to the increase in melting points, see compounds 82dd and 83dd and 84dd. These compounds have small dielectric anisotropy (in a range of 2-4). Isomeric compounds $82 \mathrm{dd}$ and 83dd differ much in their dielectric anisotropies [112].

Table 11. Phase transition temperatures $\left[{ }^{\circ} \mathrm{C}\right]$, melting enthalpies $[\mathrm{kJ} / \mathrm{mol}]$, birefringence and dielectric anisotropy of the dialkyl phenyl tolanes at reduced temperature $T_{N-\digamma} T=40 \mathrm{~K}$.

\begin{tabular}{|c|c|c|c|c|c|c|c|c|c|c|}
\hline No. & $\Delta H_{m}{ }^{0}$ & Formula & $\mathrm{Cr}$ & $\mathbf{N}$ & Iso & Ref. & $\Delta n$ & $n_{o}$ & $n_{e}$ & $\Delta \varepsilon$ \\
\hline 81dd & 19.16 & & * 33 & $* 155$ & $*$ & [112] & 0.362 & 1.490 & 1.852 & +1.0 \\
\hline 82dd & 28.7 & & * 37 & $* 121$ & $*$ & [112] & 0.354 & 1.506 & 1.860 & +1.5 \\
\hline 83dd & 27.7 & & * 54 & 91 & $*$ & [112] & 0.326 & 1.506 & 1.832 & +2.3 \\
\hline 84dd & 39.8 & & $* 63$ & $* 90$ & $*$ & [112] & 0.329 & 1.501 & 1.830 & +3.7 \\
\hline 85dd & 37.7 & & * 98 & $* 166$ & $*$ & [85] & & & & \\
\hline
\end{tabular}

It is nearly twice as high for $\mathbf{8 3 d d}$ as for $\mathbf{8 2 d d}$ : calculated dipole moments for compounds $\mathbf{8 1 d d}$, 82dd and 83dd are $0.73 \mathrm{D}, 2.00 \mathrm{D}$ and $2.5 \mathrm{D}$, respectively. The interaction of electronic clouds of the fluorine atom with triple bond via conjugated systems of bonds or via space decreases the dipole moment of the molecule. Birefringence value of compounds 81dd-85dd is in the range 0.33-0.36. They show a very small absorption in the $\mathrm{THz}$ range and have promising properties for application in this region [113].

Generally, phenyl tolanes seem to be much more profitable compounds compared to terphenyls. They have a birefringence reaching up to 0.45 at room temperature in the case of isothiocyanates for pentyl terminal chain, and furthermore, they also reach $\Delta n$ values up to 0.6 for the ethyl chain [110,111]. Their $F o M_{1}$ values are about 40 at room temperature and reach maximum value $\sim 240$ at $150{ }^{\circ} \mathrm{C}$. Their melting temperatures are lower than terphenyls'; also their melting enthalpies are rather low. Although monofluoro-substituted compounds have low melting points (see compounds 63d and 62d), smectic phases ( $\mathrm{SmE}, \mathrm{SmB}$ and $\mathrm{SmA}$ ) exist for them in a broad temperature range, while for chloro-substituted analogues only the SmA phase is observed.

Electronic spectra give information about the conjugation of the $\pi$ electron systems. Figure 11 shows the comparison of spectra of some isothiocyanatotolanes $\mathbf{6 6}$, terphenyls $\mathbf{3 2}$ and phenylethynyltolanes 96. 
Figure 11. Electronic spectra of compounds 32, 66, 66c and $96(6.0-6.5 \mu \mathrm{g} / \mathrm{mL}$ in hexane).

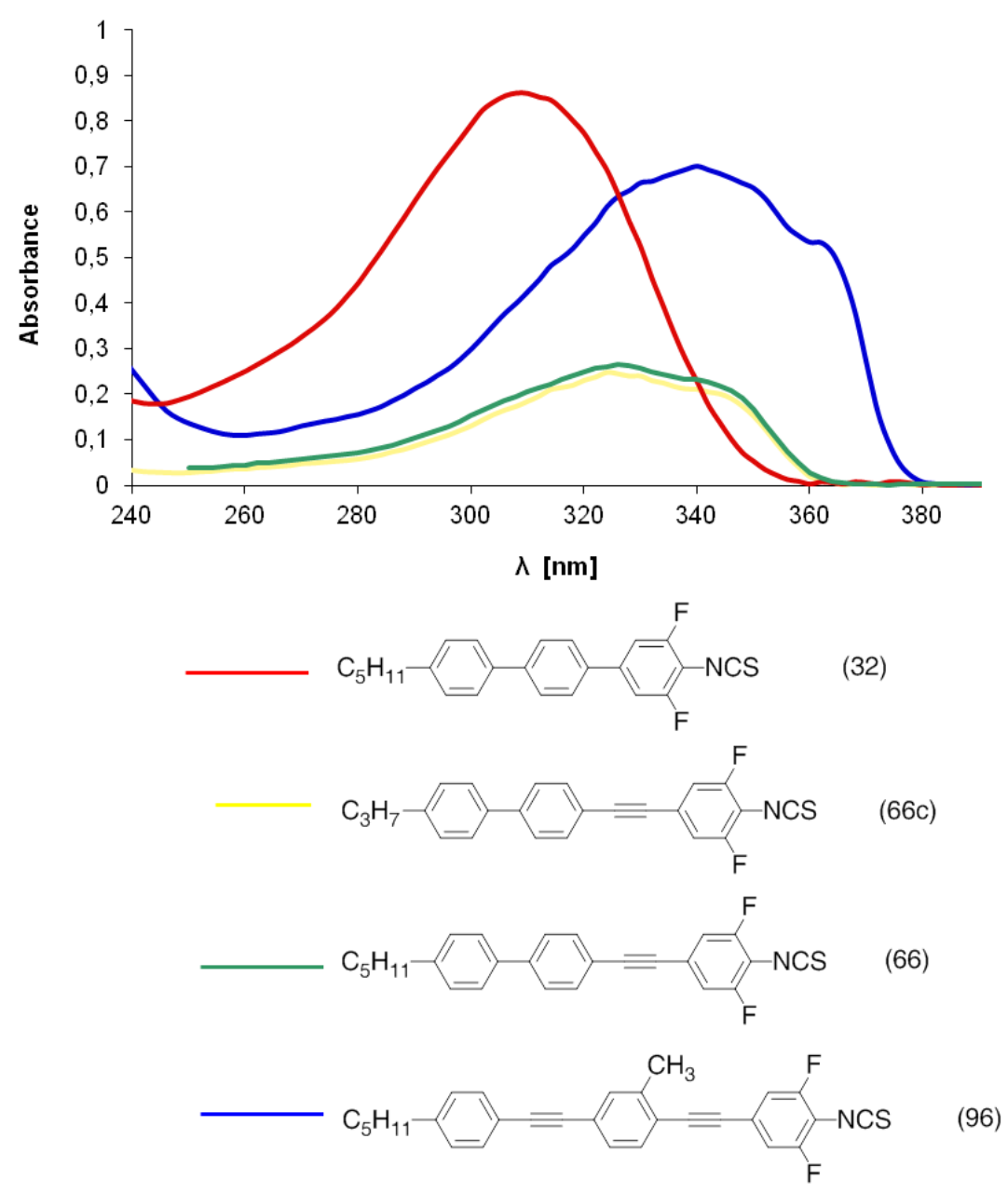

Maximum absorption is shifted to longer wavelengths. All compounds have absorption in the ultraviolet range; however, the last compound shows a close to visible range. Tolanes have broader bands than terphenyls but show lower maximum intensity.

Hird and coworkers from Hull University investigated analogues of phenyl tolanes with naphthalene moieties and butoxy or butylsulphanyl as well as cyano or isothiocyanato terminal groups [114,115]. Characteristic examples are given in Table 12.

Compounds 86d-90d, Table 12, with naphthalene moiety have a nematic phase only, but their clearing points are lower than observed for phenyltolane families, especially when the naphthalene unit is placed on the left side of molecules. Although their birefringence in case of sulphanyl derivatives reaches 0.54 , large viscosity reduces the $\mathrm{FoM}_{1}$ value. It is several times lower than that found for two-ring tolanes [49], so from the previous statements, we can assume that they may be useful for formulation mixtures wherein short response times are not important. 
Table 12. Phase transition temperatures $\left[{ }^{\circ} \mathrm{C}\right]$ and birefringence of three-ring acetylenes with naphthalene moiety.

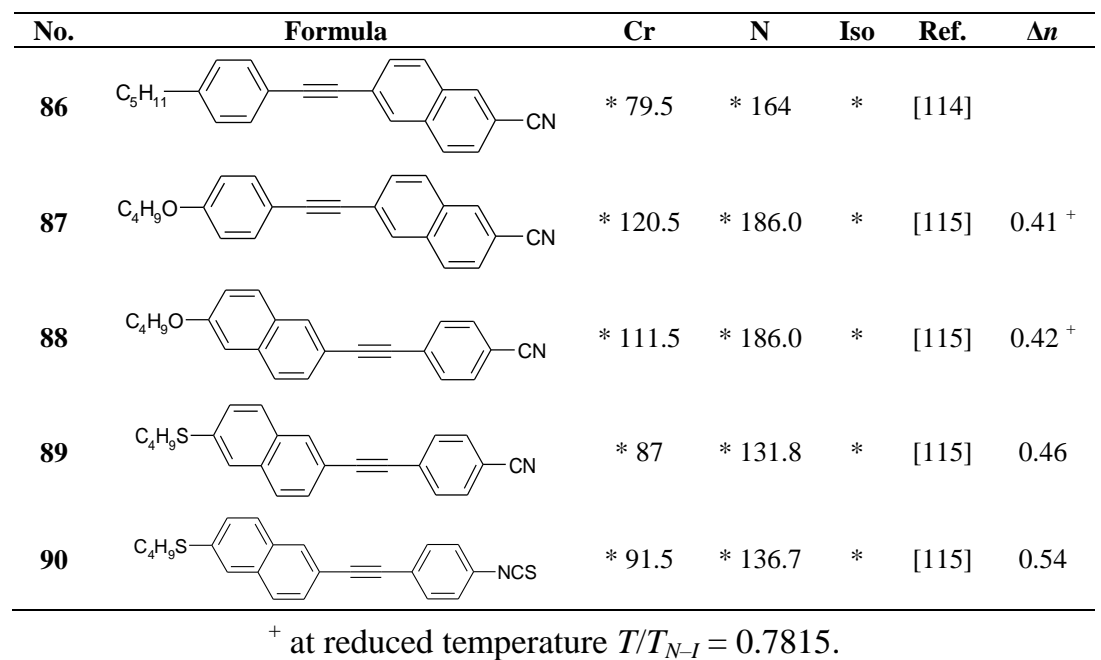

\subsubsection{Diacetylenes}

Three-ring diacetylenes laterally substituted only by the fluorine atoms are high melting nematic compounds in the case of isothiocyanato as well as cyano homologues, see Table 13, compounds $\mathbf{8 8 d}$ and 89.

Table 13. Phase transition temperatures $\left[{ }^{\circ} \mathrm{C}\right]$, melting enthalpies $[\mathrm{kJ} / \mathrm{mol}]$ and birefringence of three-ring diacetylenes.

No.


Substitution of the central ring by a methyl group leads to the compounds with a melting temperature-60 Kelvins lower in the case of isothiocyanato derivatives 90, 96- than the above mentioned compounds. In the case of fluoro terminated compound $\mathbf{9 2}$, melting temperature falls below $70{ }^{\circ} \mathrm{C}$. Inserting one or two fluorine atoms in position 3 or 3,5 (compounds 93, 96) only has a small influence on the melting temperature and melting enthalpy. The transformation of the methyl group into an ethyl one decreases the melting temperature in the range of $70-80{ }^{\circ} \mathrm{C}$. The properties of ethyl substituted isothiocyanato compound 94 and cyano ethyl substituted compound 95 are very similar. It may suggest that the cyano compound loses its ability of association in the presence of a bulk substituent. Dielectric studies confirm this observation because electric permittivity for compounds substituted with $\mathrm{CH}_{3}$ group is much higher than for compounds without it [69]. Interesting properties show also dialkyl diacetylenes substituted by fluorine atoms (compound 85dd) or by $\mathrm{OCF}_{3}$ group (compound 87ec). They are low melting nematics, especially the second one. Furthermore, what is the most surprising, its viscosity is low, only as $56 \mathrm{mPa} \cdot \mathrm{s}$. It is an unexpectedly low value for such a bulky group like $\mathrm{OCF}_{3}$, while for $\mathrm{OCH}_{3}$, the observed viscosity is $353 \mathrm{mPa} \cdot \mathrm{s}$ [116].

\subsection{Four-Ring Compounds: Quaterphenyls, Phenylethynyl Terphenyls}

Di-, tri- and tetra-fluorosubstituted isothiocyanato quaterphenyls have smectic A phase in a very broad temperature range. Melting points are also high for them, see Table 14. Clearing temperatures are very high (close to $400{ }^{\circ} \mathrm{C}$ ) for di-substituted compound 97. $T_{N-I}, T_{m}$ and $T_{S m A-N}$ temperatures systematically decrease with an increase in the number of fluorine atoms in the lateral position of molecules, but they are still above an acceptable level even for tetra substituted compounds. Also, quaterphenyls $\mathbf{1 0 0}$ and $\mathbf{1 0 1}$ terminated with fluorine atom and having additionally three or four fluorine atoms in the lateral positions are smectics A with $T_{S m A-N}$ transition at $195{ }^{\circ} \mathrm{C}$ and $166{ }^{\circ} \mathrm{C}$, respectively. Similarly structured compound 102, with $\mathrm{CF}_{2} \mathrm{O}$ bridge in the core on the right side, has a distinctly lower melting point and stability in its smectic A phase. Unfortunately, the $\mathrm{CF}_{2} \mathrm{O}$ bridge breaks conjugation among the aromatic rings and decreases $\Delta n$ values to the level 0.27 . Other property changes are very desirable [85]. Rotational viscosity $\gamma$ is lower than that observed for other such large molecules and dielectric anisotropy $\Delta \varepsilon$ increases [85]. Shortly, they are very useful components for formulation of the medium birefringence mixtures with high photochemical stability. Total depression of the smectic phase is obtained through the exchange of biphenyl unit for bicyclohexyl unit, see isothiocyanato compounds $\mathbf{1 0 5}$ c and $\mathbf{1 0 5}$ [101]. With this move, low melting compounds with an extremely broad range of nematic only phase are obtained with high $\Delta n \sim 0.35-0.4$, which is involved by way of the high order parameter of these compounds. Another interesting feature of such compounds is also its strong dependence on permittivity constant $\varepsilon_{\|}$upon frequency, which makes them excellent components for dual frequency mixtures [120]. Fluoro terminated compound 106c melts at higher temperatures but still at an acceptable level, while compounds 104c and 103c with cyano terminal group melt at unacceptably high temperatures. Such features are observed not only for compound 104c, but also for slightly different analogue substitution [121].

Only nematic phase is present in quaterphenyl derivatives 107-112 laterally substituted by more bulky moiety such as chlorine atom or methyl group [117]. 
Table 14. Phase transition temperatures $\left[{ }^{\circ} \mathrm{C}\right]$, melting enthalpies $[\mathrm{kJ} / \mathrm{mol}]$ and birefringence of four-ring compounds.

\begin{tabular}{|c|c|c|c|c|c|c|c|c|c|}
\hline No. & $\Delta H_{m}{ }^{0}$ & Formula & $\mathrm{Cr}_{1}$ & $\mathrm{Cr}$ & SmA & $\mathbf{N}$ & Iso & Ref. & $\Delta n$ \\
\hline 97 & 31.4 & & - & $* 131.0$ & * 285.0 & * 390.0 & $*$ & [122] & \\
\hline 98 & 26.8 & & - & $* 123.0$ & * 260.0 & $* 355.0$ & $*$ & [122] & \\
\hline 99 & 27.6 & & - & $* 113.0$ & * 227.0 & * 327.0 & $*$ & [122] & \\
\hline 100 & 8.7 & & - & * 115.5 & * 195.3 & $* 240.6$ & $*$ & [102] & \\
\hline $101 d^{+}$ & & & - & $* 112.0$ & * 166.0 & * 200.1 & $*$ & [3] & 0.273 \\
\hline 101 & 33.3 & & - & * 101.8 & * 167.5 & * 201.6 & * & [85] & \\
\hline 102 & & & - & * 44.8 & * 91.1 & * 141.0 & * & {$[85]$} & 0.27 \\
\hline $105 c$ & 30.1 & & - & $* 80.2$ & - & $* 350.0$ & $*$ & {$[101]$} & 0.40 \\
\hline 105 & 31.0 & & - & * 60.3 & - & $* 350.0$ & * & [101] & 0.36 \\
\hline $104 c$ & 27.3 & & - & * 159.6 & - & $* 360.0$ & $*$ & [101] & \\
\hline $106 \mathrm{c}$ & 17.6 & & * 35.5 & $* 103.1$ & - & $* 260.0$ & $*$ & [101] & \\
\hline $103 c$ & & & $* 98$ & * 133 & - & *353 & $*$ & {$[85]$} & \\
\hline 107 & 22.4 & & - & * 100 & - & $*>300$ & $*$ & [51] & 0.45 \\
\hline 108 & 28.7 & & - & $* 77.3$ & - & $* 265.0$ & $*$ & [117] & 0.45 \\
\hline 109 & 22.5 & & - & $* 115.0$ & - & * 283.0 & $*$ & {$[51]$} & 0.43 \\
\hline 110 & 28.0 & & - & * 106.6 & - & * 161.9 & $*$ & [117] & \\
\hline 111 & 24.9 & & - & $* 86.3$ & - & $* 142.0$ & $*$ & [117] & 0.44 \\
\hline 112 & 26.5 & & - & $* 95.2$ & - & * 117.0 & $*$ & [117] & \\
\hline
\end{tabular}

Compounds with one chlorine atom $(\mathbf{1 0 7}, \mathbf{1 0 8})$ or one methyl group (109) in the lateral central position still have high clearing points, while the simultaneous presence of both these groups reduces melting point, and also rapidly, the $T_{N-I}$ point. According to the authors' knowledge, compound 108 is the lowest melting alkyl isothiocyanato quaterphenyl obtained up to now. We also found that, more interesting than quaterphenyls, are their four-ring analogues with the triple bond positioned inside the core, see compounds 113-118, see Table 15.

Except for cyano compound 118, they show similar low melting temperatures and stronger nematogenic character than isothiocyanato quaterphenyls 110-112, simultaneously their $\Delta n$ is shifted to a higher range $0.53-0.55$ and $\Delta n$ increment of $\sim 0.05$ is observed as a result of the improvement in conjugation. 
Table 15. Phase transition temperatures $\left[{ }^{\circ} \mathrm{C}\right]$, melting enthalpies $[\mathrm{kJ} / \mathrm{mol}]$ and birefringence of four-ring compounds with the triple bond.

\begin{tabular}{|c|c|c|c|c|c|c|c|c|}
\hline No. & $\Delta H_{m}{ }^{0}$ & Formula & $\mathrm{Cr}$ & $\mathbf{S m A}$ & $\mathbf{N}$ & Iso & Ref. & $\Delta n$ \\
\hline 113 & 20.5 & & * 99.0 & * 195 & * 285 & $*$ & [85] & 0.54 \\
\hline 114 & 28.1 & & * 116 & & $*>300$ & * & [120] & \\
\hline 115 & 32.8 & & $* 114.7$ & - & $*>300$ & $*$ & [117] & 0.55 \\
\hline 116 & 33.6 & & * 95.9 & - & * 280.0 & $*$ & [117] & \\
\hline 117 & 24.9 & & * 83.5 & & * 211.9 & * & [117] & 0.53 \\
\hline 118 & & & * 183 & & * 331 & $*$ & [121] & \\
\hline
\end{tabular}

Four-ring diacetylenes substituted only by fluors have high melting points and smectic A phases observed in broad temperature ranges (see compound 119c, Table 16). Moderately low melting temperatures are observed only for compounds with two ethyl groups, see compounds 120, 121 [123,124]. They have large $\Delta n \sim 0.64-0.67$ values, but also very high melting enthalpies in both cases. Liquid crystal 122b with thiofluorene (dibenzothiophene) moiety is found to be the compound with the highest birefringence reported so far $(\Delta n=0.79)$, see Table 16. It is the cyano derivative, so the isothiocyanato analogue should have an even higher $\Delta n$ value. Napthalene derivatives such as compound $\mathbf{1 2 3}$ have only nematic phase in the presence of an ethyl lateral group $[125,126]$.

Other heterocyclic derivatives with benzotiazole and dibenzothiophene moiety were prepared by Sekine et al. [125,126], and they obtained compounds reaching $\Delta n=0.6$, but which have unfavorably high melting points and additionally, the absorption of light is observed at 300-400 nm.

Table 16. Phase transition temperatures $\left[{ }^{\circ} \mathrm{C}\right]$, melting enthalpies $[\mathrm{kJ} / \mathrm{mol}]$ and birefringence of four-ring diacetylenes.

No. $\quad \boldsymbol{\Delta H}_{\boldsymbol{m}}{ }^{2}$




\section{Mixture Formulation}

High birefringent compounds are not only useful for formulation of high birefringent nematic mixtures, but they are often used also as components of medium birefringent mixtures. Mixtures with eutectic composition are the most useful because they ensure the lowest melting points. To obtain them, it is necessary to mix molecules with different shapes and lengths. Two, three and four-ring molecules or compounds containing the same core and simultaneously different chains (for example propyl and pentyl or ethyl and butyl) are one possible option. The presence of small molecules in the mixture is a very effective way to obtain the nematic medium with low melting temperatures but such composition always decreases $\Delta n$.

Nonpolar hydrocarbon molecules such as alkyl, alkenyl bicyclohexanes with extremely low rotational viscosities are known [3]. Mixing them with high polar and high birefringence compounds results in mixtures with much lower viscosities than formulated directly from medium viscosity compounds [8], see Figure 12 given below:

Figure 12. Composition of mixture with low rotational viscosity $\gamma$. The mixture properties: clearing point $75{ }^{\circ} \mathrm{C}, d=3.18, d \cdot \Delta n=0.412, \Delta n=0.1297, \Delta \varepsilon=3.6, \gamma=48 \mathrm{mPa} \cdot \mathrm{s}$, $t_{\text {on }}=0.85 \mathrm{~ms}, t_{\text {off }}=3.17 \mathrm{~ms}, t_{\text {on }}+t_{\text {off }}=4.0 \mathrm{~ms}, V_{10}=2.35 \mathrm{~V}, V_{50}=2.75 \mathrm{~V}, V_{90}=3.34 \mathrm{~V} \mathrm{[8]}$.

\section{Mixture with extremely low $\gamma$}

wt. \%

$124 c$

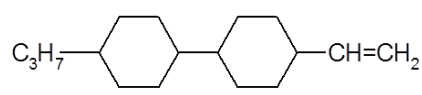

125



126

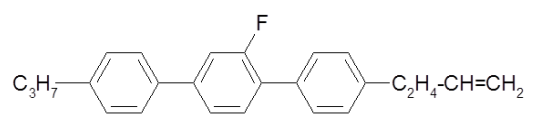

51

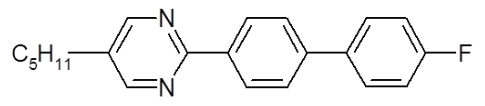

127

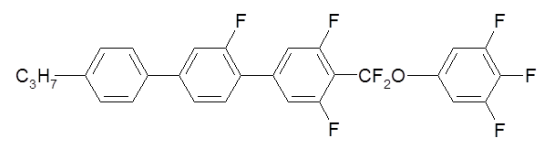

128



55.5

16.5

10.0

7.5

3.0

Extremely low viscosity mixtures may be also formulated from cyclohexylbenzene isothiocyanates, see as an example of our mixture 1284 [127] or mixture 1892 presented below, Figure 13. 
Figure 13. Medium birefringence low viscosity mixture 1892. The mixture properties: clearing point $88.6{ }^{\circ} \mathrm{C}, \Delta n=0.1891, \Delta \varepsilon=7.9, \eta=11.1 \mathrm{mPa} \cdot \mathrm{s}, t_{\text {on }}=0.1 \mathrm{~ms}, t_{\text {off }}=2.7 \mathrm{~ms}$, $V_{t h}=1.6 \mathrm{~V}, \mathrm{CR}$ (diode) of $17.4=1: 9920$.

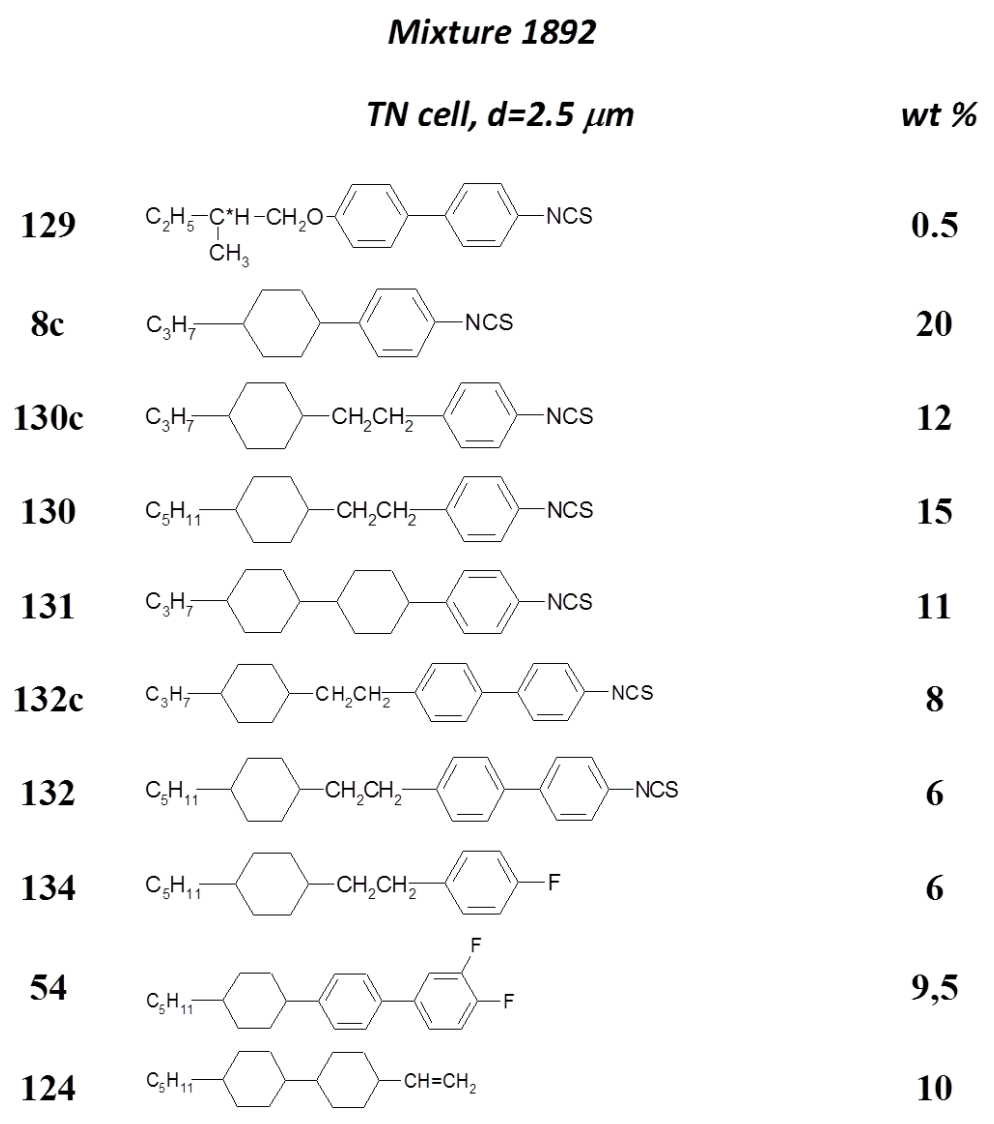

Such mixtures may be doped with high birefringence compounds and quick operating mixtures with $\Delta n$ values above 0.3 are prepared in such way as demonstrated here [51].

The main application of high birefringence compounds is of course formulation of high birefringence mixtures. Many such mixtures with $\Delta n$ values in the range $0.3-0.7$ have been demonstrated so far $[49,50,91,93,94,101,111,122,124,128]$. Mixtures with a broad range of nematic phases and birefringence values of $\Delta n=0.3-0.45$ are now available with an acceptable level of viscosity $(\gamma<300 \mathrm{mPa} \cdot \mathrm{s})$, see example Table 17.

Mixtures composed of isothiocyanates $(1631,1658,1734,1791$ and 1825) have $\Delta n$ from 0.36 to 0.43 and high $F_{0} M_{1}$ from 12 to 15, while cyano mixture BL038 has $\Delta n \sim 0.26$ and FoM $\sim 2.2$. Mixtures composed of fluoroterphenyls and fluorophenyl tolanes (1879 and 1980) have $\Delta n<0.24$.

Mixtures 1791 and 1825 composed of fluoro-substituted alkyltolane and alkylphenyl tolane isothiocyanates have the highest birefringence among those presented in Table 17. Their rotational viscosity is twice as low as cyano mixture BL038, while the FoM $M_{1}$ value is six times larger. Properties of the mixture 1825 are at this moment the best recognized. It was tested in different photonic devices working in infrared as well as $\mathrm{GHz}$ and $\mathrm{THz}$ range with a good performance $[52,129,130]$. It shows the strong dispersion of birefringence in a visible range and the small birefringence in the infrared region and $\mathrm{THz}$ region (see Figure 14), as is predicted by the Cauchy model and experimentally verified by Wu et al. [131,132]. 
Table 17. Physical properties of high birefringent mixtures prepared from isothiocyanates (1631, 1658, 1734, 1791, 1825), fluorides (1879, 1980) and cyanides (BL038).

\begin{tabular}{ccccccccc}
\hline & $\mathbf{1 6 3 1}$ & $\mathbf{1 6 5 8}$ & $\mathbf{1 7 3 4}$ & $\mathbf{1 7 9 1}$ & $\mathbf{1 8 2 5}$ & $\mathbf{1 8 7 9}$ & $\mathbf{1 9 8 0}$ & BL038 \\
\hline $\mathrm{N}-$-Iso, $\left[{ }^{\circ} \mathrm{C}\right]$ & 94 & 116 & 114 & 109 & 136.0 & 94.1 & 148.9 & 100.0 \\
$\mathrm{Cr}-(\mathrm{N}),\left[^{\circ} \mathrm{C}\right]$ & $<-5$ & $<0$ & $(-3)$ & -10 & -12 & -20 & $<-20$ & \\
$\varepsilon_{\|}$ & 15.7 & 19.8 & 22.0 & 23.6 & 25.6 & 14.6 & 4.4 & 19.4 \\
$\varepsilon_{\perp}$ & 3.9 & 4.2 & 4.4 & 6.2 & 5.0 & 4.4 & 2.9 & 5.0 \\
$\Delta \varepsilon$ & 11.8 & 15.6 & 17.6 & 17.4 & 20.6 & 10.2 & 1.5 & 14.4 \\
$\Delta \mathrm{n}(633 \mathrm{~nm})$ & 0.36 & 0.38 & 0.39 & 0.40 & 0.43 & 0.17 & $0.31 *$ & 0.257 \\
$K_{11}[\mathrm{pN}]$ & 17.6 & 21 & 26.2 & 24.7 & 20.1 & & & 19.1 \\
$K_{33}[\mathrm{pN}]$ & 34.6 & 32 & 28.1 & 25.2 & 32.1 & & & 22.4 \\
$K_{33} / K_{11}[\mathrm{pN}]$ & 1.97 & 1.5 & 1.07 & 1.02 & 1.60 & & & 1.17 \\
$\gamma_{1} / K_{11}\left[\mathrm{~ms} / \mu \mathrm{m}{ }^{2}\right]$ & 9.1 & 10.5 & 11.6 & 11.50 & 15.5 & & & 30.2 \\
$\gamma$ & 160 & 220 & 303 & 284 & 311 & & & 577 \\
FoM $[\mu \mathrm{m} / \mathrm{s}]$ & 14.5 & 13.8 & 13.1 & 13.92 & 12.6 & & & 2.2 \\
$V_{10}[\mathrm{~V}]$ & 1.7 & 1.6 & 1.7 & 1.7 & 1.04 & & & 1.6 \\
$\eta(\mathrm{mPa} \cdot \mathrm{s})$ & & & & 31 & 31 & & 45.6 & \\
\hline
\end{tabular}

$* \lambda=589 \mathrm{~nm}$.

Figure 14. Comparison of refractive indices for mixture 1825 at visible, infrared and $\mathrm{THz}$ range.

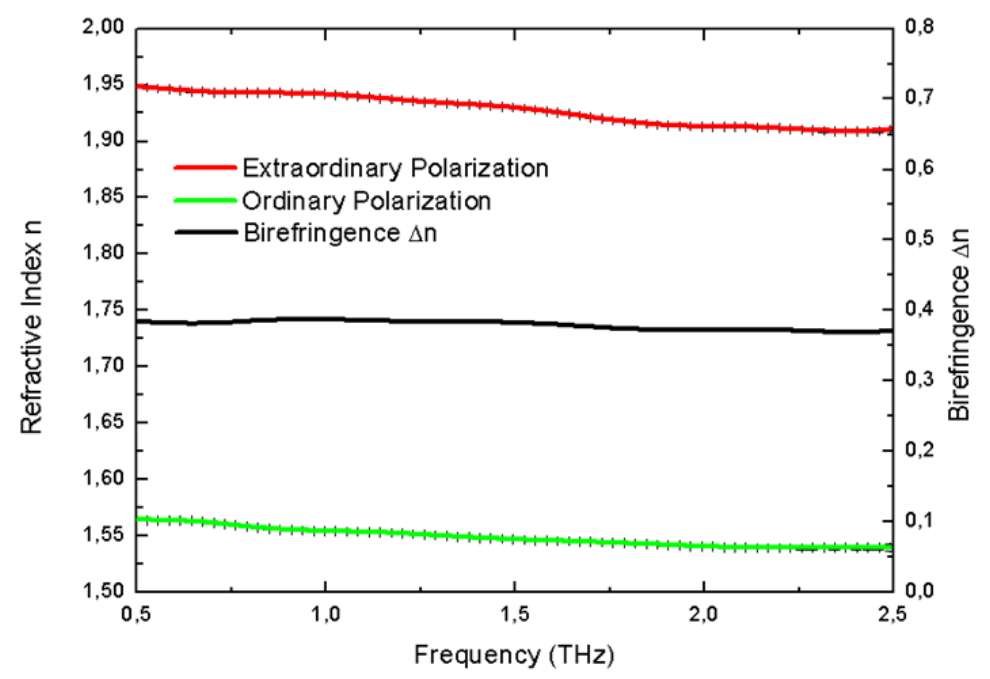

\begin{tabular}{cccc}
\hline & $\Delta \mathbf{n}$ & $\mathbf{n}_{\mathbf{0}}$ & $\mathbf{n}_{\mathrm{e}}$ \\
\hline$\lambda[\mathbf{5 9 8} \mathbf{n m}]^{*}$ & 0,42 & 1,54 & 1,96 \\
$\lambda[\mathbf{1 0 6 4} \mathbf{n m}]$ & 0,31 & 1.53 & 1.84 \\
$\lambda \mathbf{0 . 5} \mathrm{THz}$ & 0,3 & 1,67 & 1,97 \\
$\lambda 2.5 \mathrm{THz}$ & 0.3 & 1.62 & 1.92 \\
\hline
\end{tabular}

* $\Delta n$ was measured by the infrared method in wedge-shaped cells [52] and it is a little lower than given above in the main text. Optical indices in THz range were measured by M. Reuter from Koch's laboratory (Marburg University, Germany).

Refractive indices, $n_{\mathrm{e}}$ and $n_{\mathrm{o}}$, continuously decrease with the increase of $\lambda$ length in visible and infrared range; the simultaneously extraordinary index $n_{\mathrm{e}}$ value is nearly the same at $589 \mathrm{~nm}$ and $0.5 \mathrm{THz}$ and the ordinary index $n_{\mathrm{o}}$ value is higher at $\mathrm{THz}$ than in the visible range [85]. The level of absorption losses of mixtures composed of isothiocyanates, cyanides and fluorides (absorption coefficient $\alpha_{\mathrm{e}}$ and $\alpha_{\mathrm{o}}$ ) decreases as follows in THz region [133].

$\mathrm{CN}>\mathrm{NCS}>\mathrm{F}$

The absorption coefficients $\alpha_{\mathrm{o}}$ and $\alpha_{\mathrm{e}}$ change as follows:

$\alpha_{\mathrm{e}} \mathrm{NCS}>\mathrm{CN}>\mathrm{F}$ 
$\alpha_{\mathrm{o}} \mathrm{CN}>\mathrm{F} \approx \mathrm{NCS}$

$\alpha_{\mathrm{e}}$ is the absorption coefficient for polarization along the long axis and $\alpha_{\mathrm{o}}$ is the absorption coefficient for polarization along the short molecular axis.

Mixture consisting simultaneously of isothiocyanato compounds and cyano- or fluoro compounds has the best properties obtained so far. They exhibit not only reduced absorption losses but also a small dichroism because $\alpha_{\mathrm{e}}$ and $\alpha_{\mathrm{o}}$ of the component are averaged and levels them out [133].

Also, there was recently demonstrated high birefringent mixtures through a dual addressed technique operating with a symmetric response time $t_{o n} \sim t_{\text {off }} \sim 0.5 \mathrm{~ms}[120]$.

\section{Conclusions}

High birefringence liquid crystal mixtures are necessary for application in visible, infrared, $\mathrm{GHz}$ and $\mathrm{THz}$ ranges of electromagnetic radiation. So far, we have designed an interesting liquid crystal medium with positive dielectric anisotropy and birefringence of up to $\Delta n=0.3-0.48$, an acceptable level of viscosity. Still, mixture with birefringence larger than $\Delta n=0.5-0.6$ is a serious problem and needs to be considered carefully. For long-time operating devices working in visible range or blue phase mode, it is also necessary to maintain high photochemical stability in materials. Such properties may ensure that mixtures consisting of fluorine contain liquid crystalline compounds. At the moment, liquid crystal mixtures within the range of $\Delta n=0.25-0.35$ are possible to formulate. Here, phenyl tolanes and diacetylene like compounds 80-85 and 92 seem to be very useful. Furthermore, we believe that it is necessary to design and prepare more such structured compounds. Mixture consisting of cyanides may reach a slightly higher birefringence, even up to 0.4 . These compounds are nematogens even under an absence of lateral substituents, but the main problem that appears, especially for four-ring systems, is that high melting points are still observed, which leads to the low solubility of such multi-ring compounds. They are also much more viscous than fluorides and isothiocyanates as the result of dimerization. Mixing cyanides with fluorides and/or isothiocyanates may very often lead to interesting results; the resulting issue is as follows: dimerization ability is decreased and viscosity falls. This phenomenon is also accompanying the decrease of $T_{N-I}$ temperature and the increase of dielectric anisotropy $\Delta \varepsilon$; simultaneously, a depression of smectic phases is observed. Mixtures consisting of isothiocyanates and cyanides also have smaller absorption coefficients (smaller losses) and lower absorption dichroism at the $\mathrm{THz}$ region. The highest values of birefringence are possible to obtain from isothiocyanates $-\Delta n$ may level up to 0.7 at $589 \mathrm{~nm}$ and most likely, there is also a possibility to reach above $\Delta n=0.8$ values. It seems that, in particular, compounds with a thiofluorene moiety should provide the best way to improve conjugate systems. Although such a possibility exists, all liquid crystal mixtures with moderate viscosity have been formulated so far with $\Delta n<0.5$. Tolanes, phenyl tolanes and bistolanes (triphenyl diacetylenes) seem to be much better components for mixture formulation compared to terphenyl and quaterphenyl derivatives. They ensure better conjugation between $\pi$ electrons inside molecules. There is also experimentally observed an increment of increase of $\Delta n$ values even of 0.1 , especially in four-ring systems with additional two triple bonds in comparison to the calculated values from the characteristic input of a single unit, see Figure 15. 
Figure 15. Predicted and observed birefringence values in differently conjugated compounds, consisting of benzene rings and triple bonds.

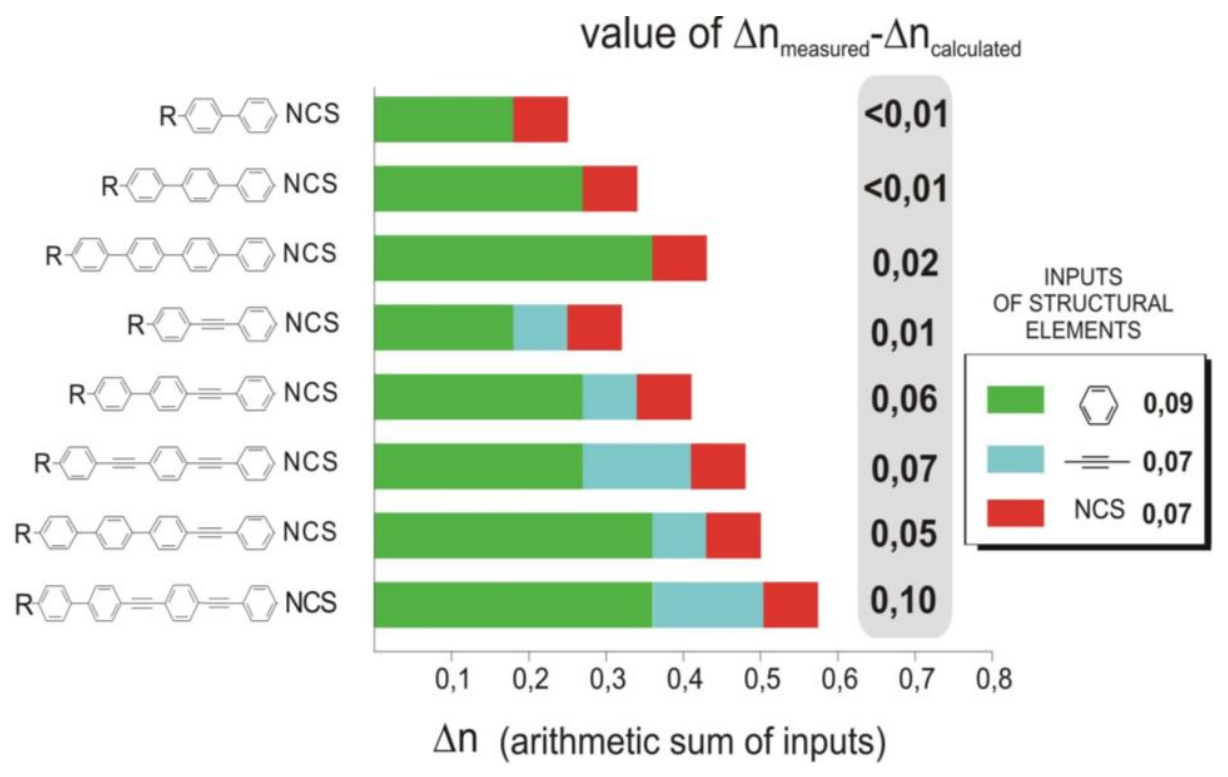

Additional phenyl tolanes and bitolanes with more effective positions of lateral substituents, also possessing thiophene or thiofluorene moiety, are necessary. The main inconvenience of isothiocyanato compounds is their high smectogenity. In the early part of this review, the experimental results were presented, showing relations between the molecules structure and observed temperature ranges of mesophases. There are three main ways to depress the presence of smectic phases in liquid crystal molecules, see Figure 16.

Figure 16. Influence of different molecular units on the birefringence values.

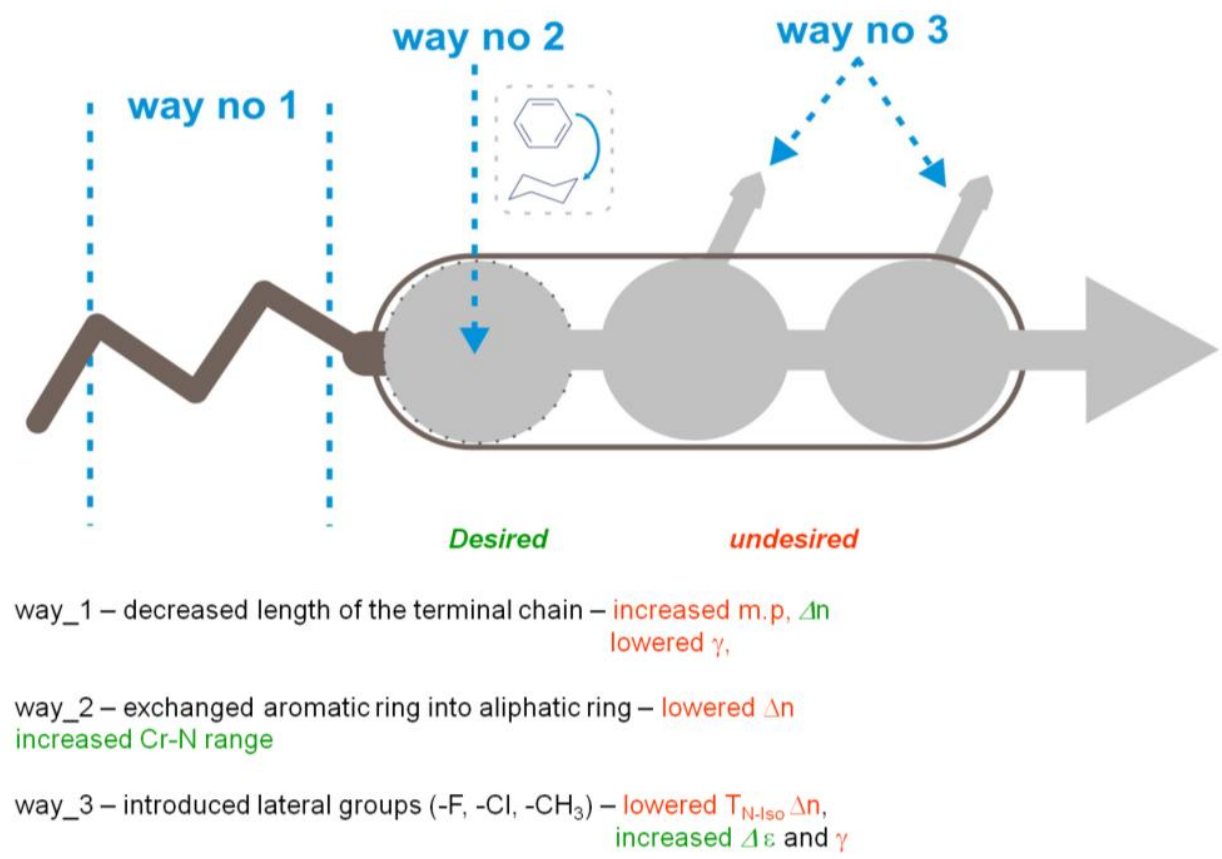

They may simultaneously increase or decrease birefringence as well as for viscosity. As is presented, the accompanying changes may not proceed in the desired direction. Shortening the alkyl 
chain is a very effective way to increase the birefringence and decrease viscosity, but often it is practically impossible from an experimental point of view because of the high melting points observed for compounds with short alkyl chains such as methyl, ethyl or propyl chains. However, melting temperature changes occur very irregularly; sometimes it is possible to find a liquid crystal family with low melting points for first homologues. The exchange of the left side benzene ring (one or two) into cyclohexane always involves a drastic destabilization of smectic phases. Very often viscosity is effectively lowered for such systems but simultaneously birefringence always decreases, which is partially compensated by the increase of the order parameter. The introduction of lateral substituents such as fluorine atoms in the case of two-ring compounds, or more fluorine atoms or even bulky substituents such as the chlorine atom, and methyl andethyl group in the case of three and four-ring compounds, effectively destabilizes smectic phases but always involves a decrease in $T_{N-I}$ temperature, $\Delta n$ and an increase of $\gamma$. In the case of substitution by fluorine and chlorine atoms, the increase of $\Delta \varepsilon$ may be observed as well.

\section{Acknowledgments}

Work was supported by the PBS 847 grant and Military University of Technology grant 08-714.

\section{Conflicts of Interest}

The authors declare no conflict of interest.

\section{References}

1. Kirsch, P.; Bremer, M. Nematic liquid crystals for active matrix displays: Molecular design and synthesis. Angew. Chem. Int. Ed. 2000, 39, 4216-4235.

2. Iwashita, Y.; Kaneoya, M.; Takeuchi, K.; Takehara S.; Takatsu, H. Physical property of new liquid crystal materials and mixture design for active matrix LCD. Mol. Cryst. Liq. Cryst. 2001, 364, 851-858.

3. Pauluth, D.; Tarumi, K. Advanced liquid crystals for television. J. Mater. Chem. 2004, 14, 1219-1227.

4. Breddels, P.A. Trends and advances in developments of liquid crystal mixtures for TFT LCDs. In Proceedings of the 12th International Topical Meeting on Optics of Liquid Crystals (OLC'07), Puebla City, Mexico, 1-5 October 2007; pp. 17-20.

5. Demus, D.; Goto, Y.; Sawada, S.; Nakagawa, E.; Saito, H.; Tarao, R. Trifluorinated liquid crystals for TFT displays. Mol. Cryst. Liq. Cryst. 1995, 260, 1-22.

6. Kirch, P. Applications of Organofluorine Compounds. In Modern Fluoroorganic Chemistry: Synthesis, Reactivity, Applications; Willey-VCH Verlag GmbH: Weinhaim, Germany, 2004; pp. 213-225.

7. Schadt, M. Linear and non-linear liquid crystal materials, electro-optical effects and surface interactions. Their application in present and future devices. Liq. Cryst. 1993, 14, 73-104.

8. Kelun, S.M.; Yi-Hsuan, L.C.; Jer-Lin, C.F.; Mark, V. Liquid crystalline medium and liquid crystal display. WO 2,009,115,226 A1. 24 September 2009. 
9. Nishiyama, K.; Okita, M.; Kawaguchi, S.; Teranishi, K.; Takamatsu, R. 32" WXGA LCD TV using OCB mode, low temperature p-Si TFT and Blinking Backlight Technology. SID Int. Symp. Dig. Tech. 2005, 36, 132-135.

10. Harbers, G.; Hoelen, C. High performance LCD backlight using high intensity red, green and blue light emitting diodes. SID Int. Symp. Dig. Tech. 2001, 32, 702-705.

11. Gauza, S.; Zhu, X.; Piecek, W.; Dąbrowski, R.; Wu, S.T. Fast switching liquid crystals for color-sequential LCDs. J. Display Technol. 2007, 3, 250-252.

12. Kikuchi, H.; Higuchi, H.; Haseba, Y.; Iwata, T. Fast electro-optical switching in polymer-stabilized liquid crystalline blue phases for display application. SID Int. Symp. Dig. Tech. 2007, 38, 1737-1740.

13. Rao, L.; Ge, Z.; Wu, S.T.; Lee, S.H. Low voltage blue-phase liquid crystal displays. Appl. Phys. Lett. 2009, 95, 231101:1-231101:3.

14. Yan, J.; Rao, L.; Jiao, M.; Li, Y.; Cheng, H.H.; Wu, S.T. Polymer-stabilized optically isotropic liquid crystals for next-generation display and photonics applications. J. Mater. Chem. 2011, 21, 7870-7877.

15. Wang, C.T.; Wang, W.Y.; Lin, T.H. A stable and switchable uniform lying helix structure in cholesteric liquid crystals. Appl. Phys. Lett. 2011, 99, 041108:1-041108:3.

16. Wu, S.T.; Margerum, J.D.; Meng, H.B.; Hsu, C.S.; Dalton, L.R. Potential liquid crystal mixtures for $\mathrm{CO}_{2}$ laser application. Appl. Phys. Lett. 1994, 64, 1204-1206.

17. Wu, S.T. Infrared properties of liquid crystals: An overview. Opt. Eng. 1987, 26, 120-128.

18. Nie, X.Y.; Wu, T.X.; Lu, Y.Q.; Wu, Y.H.; Liang, X.; Wu, S.T. Dual-frequency addressed infrared liquid crystal phase modulators with submillisecond response time. Mol. Cryst. Liq. Cryst. 2006, 454, 123-133.

19. Kleine-Ostmann, T.; Nagatsuma, T. A review on Terahertz communications research. J. Infrared Millim. Terahertz Waves 2011, 32, 143-171.

20. Palffy-Muhoray, P.; Cao, W.; Moreira, M.; Taheri, B.; Munoz, A. Photonics and lasing in liquid crystal materials. Philos. Trans. R. Soc. A 2006, 364, 2747-2761.

21. Coles, H.; Morris, S. Liquid-crystal lasers. Nat. Photonics 2012, 4, 676-684.

22. Urbas, A.M.; Brown, D.P. Liquid crystals in metamaterials. In Liquid Crystals Beyond Displays: Chemistry, Physics, and Applications; Li, O., Ed.; John Wiley \& Sons, Inc.: Hoboken, NJ, USA, 2012; pp. 379-402.

23. Khoo, I.C.; Werner, D.H.; Liang, X.; Diaz, A.; Weiner, B. Nanosphere dispersed liquid crystals for tunable negative-zero-positive index of refraction in the optical and terahertz regimes. Opt. Lett. 2006, 31, 2592-2594.

24. Pratibha, R.; Park, K.; Smalyukh, I.I.; Park, W. Tunable optical metamaterial based on liquid crystal-gold nanosphere composite. Opt. Express 2009, 17, 19459-19469.

25. Lavrentovich, O.D. Liquid crystals, photonic crystals, metamaterials, and transformation optics. Proc. Natl. Acad. Sci. USA 2011, 108, 5143-5144.

26. Jesacher, A.; Maurer, C.; Schwaighofer, A.; Bernet, S.; Ritsch-Marte, M. Near-perfect hologram reconstruction with a spatial light modulator. Opt. Express 2008, 16, 2597-2603.

27. Curatu, G.; Harvey, J.E. Analysis and design of wide-angle foveated optical systems based on transmissive liquid-crystal spatial light modulators. Opt. Eng. 2009, 48, doi:10.1117/1.3122006. 
28. Scherger, B.; Reuter, M.; Scheller, M.; Altmann, K.; Vieweg, N.; Dabrowski, R.; Deibel, J.A.; Koch, M. Discrete Terahertz beam steering with an electrically controlled liquid crystal device. $J$. Infrared Millim. Terahertz Waves 2012, 33, 1117-1122.

29. Khan, S.A.; Riza, N.A. Demonstration of 3-dimensional wide angle laser beam scanner using liquid-crystals. Opt. Express 2004, 12, 868-882.

30. Kim, J.; Oh, C.; Escuti, M.J.; Hosting, L.; Serati, S. Wide-angle, nonmechanical beam steering using thin liquid crystal polarization gratings. Adv. Wavefront Control Methods Devices Appl. VI 2008, doi:10.1117/12.795752.

31. Grudniewski, T.; Parka, J.; Dąbrowski, R.; Stolarz, Z.; Miniewicz, A. Photorefractive effects in pure multicomponent isothiocyanate liquid crystals under low power illumination. Mol. Cryst. Liq. Cryst. 2004, 413, 443-450.

32. Miniewicz, A.; Gniewek, A.; Parka, J. Liquid crystals photonic applications. Opt. Mater. 2003, 21, 605-610.

33. Wilk, R.; Vieweg, N.; Kopschinski, O.; Koch, M. Liquid crystal based electrically switchable Bragg structure for THz waves. Opt. Express 2009, 17, 7377-7382.

34. Dubois, F.; Krasinski, F.; Splingart, B.; Tentillier, N.; Legrand, Ch.; Spadło, A.; Dabrowski, R. Large microwave birefringence liquid-crystal characterization for phase shifter applications. Jpn. J. Appl. Phys. 2008, 47, 3564-3567.

35. Wu, H.Y.; Hsieh, C.F.; Tang, T.T.; Pan, R.P.; Pan, C.L. Electrically tunable room-temperature liquid crystal terahertz phase shifter. IEEE Photonic Technol. L. 2006, 18, 1488-1490.

36. Garbovskiy, Y.; Zagorodnii, V.; Krivosik, P.; Lovejoy, J.; Camley, R.E.; Celinski, Z.; Glushchenko, A.; Dziaduszek, J.; Dąbrowski, R. Liquid crystal phase shifters at millimeter wave frequencies. J. Appl. Phys. 2012, 111, 054504:1-054504:4.

37. Raszewski, Z.; Kruszelnicki-Nowinowski, E.; Kędzierski, J.; Perkowski, P.; Piecek, W.; Dąbrowski, R.; Morawiak, P.; Ogrodnik, K. Electrically tunable liquid crystal filters. Mol. Cryst. Liq. Cryst. 2010, 525, 125-140.

38. Pan, C.L.; Pan, R.P. Recent progress in liquid crystal THz optics. Liq. Cryst. Mater. Devices Appl. XI 2006, 6135, doi:10.1117/12.644527.

39. Vieweg, N.; Born, N.; Al-Naib, I.; Koch, M. Electrically tunable terahertz notch filters. $J$. Infrared Millim. Terahertz Waves.2012, 33, 327-332.

40. Urruchi,V.; Marcos, C.; Torrecilla, J.; Sánchez-Pena, J.M.; Garbat, K. Note: Tunable notch filter based on liquid crystal technology for microwave applications. Rev. Sci. Instrum. 2013, 84, doi:10.1063/1.4790555.

41. Chang, C.M.A.; Cheng, C.C.; Yeh, J.A. Analysis and modeling of liquid-crystal tunable capacitors. IEEE Trans. Electron Dev. 2006, 53, 1675-1682.

42. Bildik, S.; Dieter, S.; Fritzsch, C.; Frei, M.; Fischer, C.; Menzel, W.; Jakoby, R. Reconfigurable liquid crystal reflectarray with extended tunable phase range. In Proceedings of the 8th European Radar Conference, Manchester, NH, USA, 14 October 2011; pp. 404-407.

43. Pishnyak, O.; Sato, S.; Lavrentovich, O.D. Electrically tunable lens based on a dual-frequency nematic liquid crystal. Appl. Optics 2006, 45, 4576-4582.

44. Valley, P.; Mathine, D.L.; Dodge, R.M.; Schwiegerling, J.; Peyman, G.; Peyghambarian, N. Tunable-focus flat liquid-crystal diffractive lens. Opt. Lett. 2010, 35, 336-338. 
45. Wolinski, T.R.; Ertman, S.; Lesiak, P.; Domański, A.W.; Czapla, A.; Dąbrowski, R.; Nowinowski-Kruszelnicki, E.; Wójcik, J. Photonic liquid crystal fibers-A new challenge for fiber optics and liquid crystals photonics. Opto-Electron. Rev. 2006, 14, 329-334.

46. O’Neill, M.; Kelly, S.M. Ordered materials for organic electronic and photonics. Adv. Mater. 2011, 23, 566-584.

47. Beeckman, J.; Neyts, K.; Vanbrabant, P.J.M. Liquid-crystal photonic applications. Opt. Eng. 2011, 50, doi:10.1117/1.3565046.

48. Seed, A.J.; Cross, G.J.; Toyne, K.J.; Goodby, J.W. Novel, highly polarizable thiophene derivatives for use in nonlinear optical applications. Liq. Cryst. 2003, 30, 1089-1107.

49. Gauza, S.; Wang, H.; Wen, C.H.; Wu, S.T.; Seed, A.; Dabrowski, R. High birefringence isothiocyanato tolane liquid crystals. Jpn. J. Appl. Phys. 2003, 42, 3463-3466.

50. Gauza, S.; Wen, C.-H.; Zhao, Y.; Wu, S.T.; Ziółek, A.; Dabrowski, R. Isothiocyanato-tolanes based high birefringence and fast response time mixtures for photonic applications. Mol. Cryst. Liq. Cryst. 2006, 453, 215-226.

51. Dabrowski, R.; Dziaduszek, J.; Ziółek, A.; Szczuciński, Ł.; Stolarz, Z.; Sasnouski, G.; Bezborodov, V.; Lapanik, W.; Gauza, S.; Wu, S.T. Low viscosity, high birefringence liquid crystalline compounds and mixtures. Opto-Electron. Rev. 2007, 15, 47-51.

52. Nowinowski-Kruszelnicki, E.; Kędzierski, J.; Raszewski, Z.; Jaroszewicz, L.; Dąbrowski, R.; Kojdecki, M.; Piecek, W.; Perkowski, P.; Garbat, K.; Olifierczuk, M.; et al. High birefringence liquid crystal mixtures for electro-optical devices. Opt. Appl. 2012, 42, 167-180.

53. Dąbrowski, R.; Ważyska, B.; Sosnowska, B. Creation of a nematic phase in mixtures of smectic $\mathrm{A}_{1}$ phases. Liq. Cryst. 1986, 1, 415-428.

54. Dabrowski, R.; Szulc, J. Binary systems of smectics A with enhanced nematic phase. $J$. Phys. 1984, 45, 1213-1222.

55. Dąbrowski, R.; Czupryński, K. Nematic phases created in binary mixtures of smectics A. Mol. Cryst. Liq. Cryst. 1987, 146, 341-366.

56. Czupryński, K.; Dąbrowski, R.; Przedmojski, J. Effect of properties of the smectic $A_{d}$ phase on the induction of a nematic phase in binary mixtures of smectics $\mathrm{A}_{1}$ and $\mathrm{A}_{\mathrm{d}}$. Liq. Cryst. 1989, 4, 429-433.

57. Czupryński, K.; Dąbrowski, R.; Baran, J.; Żywociński, A.; Przedmojski, J. A nematic gap in mixtures of smectics $\mathrm{A}_{1}$ and $\mathrm{A}_{\mathrm{d}}$. J. Phys. 1986, 47, 1577-1585.

58. Domon, M.; Billard, J. Écarts a l'idéalité de solutions smectiques binaries. J. Phys. Colloques 1979, 40, 413-418.

59. Sadowska, K.W.; Żywocinski, A.; Stecki, J.; Dabrowski, R. Induced smectic phases. Densities of binary mixtures of 4,4'-dialkylazoxybenzenes with 4-pentyl-4'-cyanobiphenyl (PCB). J. Phys. 1982, 43, 1673-1678.

60. Dąbrowski, R.; Czupryński, K. Chapter 8: Induced smectic and nematic phases and re-entrant phenomena. In Modern Topics in Liquid Crystals: From Neutron Scattering to Ferroelectricity; Buka, A., Ed.; World Scientific Pub. Co. Inc.: Singapore, 1993; pp. 125-160.

61. Demus, D.; Fietkau, Ch.; Schubert, R.; Kehlen, H. Calculation and experimental verification of eutectic systems with nematic phases. Mol. Cryst. Liq. Cryst. 1974, 25, 215-232. 
62. Atkins, P.W. Equilibrium. In Physical Chemistry: Science of Biology, 6th ed.; W.H. Freeman \& Company: New York, NY, USA, 1997; pp. 620-652.

63. Xianyu, H.; Wu, S.-T.; Lin, C.L. Dual frequency liquid crystals: A review. Liq. Cryst. 2009, 36, 717-726.

64. Wu, S.T.; Lackner, A.M.; Efron, U. Optimal operation temperature of liquid-crystal modulators. Appl. Optics 1987, 26, 3441-3445.

65. Smith, G.W. Phase behavior of some linear polyphenyls. Mol. Cryst. Liq. Cryst. 1979, 49, 207-209.

66. Miyazawa, K.; Kato, T.; Itoh, M.; Ushioda, M. First synthesis of liquid crystalline 2,3-bis(trifluo-romethyl)phenyl derivatives exhibiting large negative dielectric anisotropy. Liq. Cryst. 2002, 29, 1483-1490.

67. Leadbetter, A.J.; Richardson, R.M.; Colling, C.N. The structure of a number of nematogens. $J$. Phys. Colloq. 1975, 36, 37-43.

68. Longa, L.; Dejeu, W.H. Microscopic one-particle description of reentrant behavior in nematic liquid crystals. Phys. Rev. A 1982, 26, 1632-1647.

69. Jadżyn, J.; Swiergiel, J.; Plowas, I.; Dabrowski, R.; Sokolowska, U. Dipolar aggregation and the static dielectric permittivity of some liquid crystalline materials. Ind. Eng. Chem. Res. 2013, 52, 4109-4112.

70. Sarkar, P.; Mandal, P.; Paul, S.; Paul, R.; Dąbrowski, R.; Czupryński, K. X-ray diffraction, optical birefringence, dielectric and phase transition properties of the long homologous series of nematogens 4-(trans-4'-n-alkylcyclohexyl)isothiocyanatobenzenes. Liq. Cryst. 2003, 30, 507-527.

71. Hird, M. Fluorinated liquid crystals-Properties and applications. Chem. Soc. Rev. 2007, 36, 2070-2095.

72. Cross, G.J.; Seed, A.J.; Toyne, K.J.; Goodby, J.W.; Hird, M.; Artal, M.C. Synthesis, transition temperatures, and optical properties of compounds with simple phenyl units linked by double bond, triple bond, ester or propiolate linkages. J. Mater. Chem. 2000, 10, 1555-1563.

73. Gray, G.W.; Harrison, K.J.; Nash, J.A. Stable, low melting nematogens of positive dielectric anisotropy for display devices. Abstr. Pap. Am. Chem. S 1973, 142-142.

74. Gray, G.W.; Harrison, K.J.; Nash, J.A. Recent developments concerning biphenyl mesogens and structurally related compounds. In Liquid Crystals; Chandrasekhar, S., Ed.; Wikipedia: Bangalore, India, 1973; pp. 381-396.

75. Urban, S.; Czupryński, K.; Dąbrowski, R.; Gestblom, B.; Janik, J.; Kresse, H.; Schmalfuss, H. Dielectric studies of the the 4-n-alkyl-4'-isothiocyanatobiphenyl (NBT) homologous series $(n=2-10)$ in the isotropic and E phases. Liq. Cryst. 2001, 28, 691-696.

76. Raszewski, Z. Dielectric studies of binary liquid-crystalline mixtures. Liq. Cryst. 1988, 3, 307-322.

77. Dąbrowski, R.; Żytyński, E. Mesomorphic properties of 4-n-pentylbiphenyl derivatives. Mol. Cryst. Liq. Cryst. 1982, 87, 109-135. 
78. Ziółek, A.; Dąbrowski, R.; Spadło, A.; Kula, P.; Kenig, K.; Gauza, S.; Wu, S.T.; Lapanik, V. Synthesis and mesomorphic properties of fluoro substituted isothiocyanatobiphenyls and isothiocyanatoterphenyls. In Proceedings of the 16th Conference on Liquid Crystals (Chemistry, Physics and Applications), Stare Jabłonki, Poland, 18 September 2005; pp. 71-76.

79. Schmidt, W.; Vögtle, F.; Poetsch, E. Spiro units as building blocks in thermotropic liquid crystals: Synthesis and physical properties of terminally substituted spiro[5.5]undecanes. Liebigs Ann. 1995, 7, 1319-1326.

80. Schadt, M.; Buchecker, R.; Villiger, A.; Leenhouts, F.; Fromm, J. The cooperative effects of heterocycles, NCS-polar groups and double bonds on the material properties of new nematic liquid crystals. IEEE T. Electron. Dev. 1986, 33, 1187-1194.

81. Schadt, M. Nematic liquid crystals and electro-optical effects: Display applications. Chimia 1987, 41, 347-357.

82. Boller, A.; Cereghetti, M.; Schadt, M.; Scherrer, H. Synthesis and some physical properties of phenylpyrimidines. Mol. Cryst. Liq. Cryst. 1977, 42, 215-231.

83. Dąbrowski, R.; Dziaduszek, J.; Szczuciński, T. Mesomorphic characteristics of some new homologous series with the isothiocyanato terminal group. Mol. Cryst. Liq. Cryst. 1985, 124, 241-257.

84. Baran, J.W.; Raszewski, Z.; Dabrowski, R.; Kędzierski, J.; Rutkowska, J. Some physical properties of mesogenic 4-(trans-4'-n-alkylcyclohexyl)isothiocyanatobenzenes. Mol. Cryst. Liq. Cryst. 1985, 123, 237-245.

85. Dabrowski, R.; Kula, P.; Herman, J. Synthesis of new high birefringence liquid crystals. Military University of Technology, Warsaw, Poland. Unpublished work, 2013.

86. Hird, M.; Seed, A.J.; Toyne, K.J.; Goodby, J.W.; Gray, G.W.; Mcdonnell, D.G. Synthesis, transition temperatures and optical anisotropy of some isothiocyanato-substituted biphenyls. J. Mater. Chem. 1993, 3, 851-859.

87. Kedziora, P.; Jadżyn, J. Dipole dipole association of mesogenic molecules in solution. Liq. Cryst. 1990, 8, 445-450.

88. Majewska, P.; Rospenk, M.; Czarnik-Matusewicz, B.; Kochel, A.; Sobczyk, L.; Dąbrowski, R. X-ray diffraction, DFT theoretical and IR polarized spectroscopic studies of the crystal-like E-mesophase of 4'-hexyloxy-isothiocyanatotolane (6OTOLT). Chem. Phys. 2007, 340, 227-236.

89. Majewska, P.; Rospenk, M.; Petrus, R.; Sobczyk, L.; Czarnik-Matusewicz, B.; Dabrowski, R. Study of packing of 4'-butyl-4-isothiocyanatotolane by X-ray diffraction and infrared spectra in polarized light. Chem. Phys. Lett. 2012, 535, 56-62.

90. Antos, K.; Martvon, A.; Krystian, P. Dipole moments and structure of isothiocyanates. Collect. Czech. Chem. Commun. 1966, 31, 3737-3743.

91. Spadło, A.; Dąbrowski, R.; Filipowicz, M.; Stolarz, Z.; Przedmojski, J.; Gauza, S.; Fan, C.Y.; $\mathrm{Wu}$, S.T. Synthesis, mesomorphic and optic properties of isothiocyanatotolanes. Liq. Cryst. 2003, 30, 191-198.

92. Spadło, A.; Dąbrowski, R.; Filipowicz, M.; Gauza, S.; Wu, S.T. Synthesis, mesomorphic and optical properties of 4'-alkyl-3,5-difluoro-4-isothiocyanatotolanes and 4'-alkylphenyl-3,5difluoro-4-isothiocyanatotolanes. In Proceedings of the 16th Conference on Liquid Crystals (Chemistry, Physics and Applications), Stare Jabłonki, Poland, 18 September 2005; pp. 53-58. 
93. Spadło, A.; Drzewiński, J.; Dąbrowski, R.; Filipowicz, M.; Stolarz, Z.; Ścibior, E.; Kędzierski, J.; Urban, S.; Gauza, S.; Wu, S.T. Synthesis and mesomorphic properties of fluoro- and chloro-substituted isothiocyanatotolanes. In Proceedings of the 15th Conference on Liquid Crystals, Zakopane, Poland, 1 September 2004; pp. 19-25.

94. Spadło, A.; Dabrowski, R.; Dziaduszek, J.; Urban, S.; Scibior, E.; Gauza, S.; Wu. S.T. Liquid crystalline materials with high birefringence. J. Opt. Technol. 2005, 72, 659-661.

95. Hsu, C.S.; Tsay, K.T.; Chang, A.C.; Wang, S.R.; Wu, S.T. Synthesis of fluorinated naphthylphenylacetylenic and naphthylphenyldiacetylenic liquid crystals. Liq. Cryst. 1995, 19, 409-414.

96. Gray, G.W.; Mosley, A. Mesomorphic transition temperatures for the homologous series of 4- $n$-alkyl-4'-cyanotolanes and other related compounds. Mol. Cryst. Liq. Cryst. 1976, 37, 213-231.

97. Urban, S.; Czub, J.; Dąbrowski, R.; Kresse, H. Dielectric studies of tolane derivatives exhibiting the E and K phases. Liq. Cryst. 2005, 32, 119-124.

98. Adomenas, P.; Butkas, V.; Daugvila, J.; Dienyte, J.; Girdzunaite, D. Advances in Liquid Crystal Research and Applications; Bata, L., Ed.; Pergamon Press: Oxford, UK, 27-31 August 1979; pp. 1029-1038.

99. Grant, B.; Clecak, N.J.; Cox, J.R. Novel liquid crystalline materials: Synthesis and preliminary characterization of new 4,4'-disubstituted diphenyldiacetylene, tolane and stilbene derivatives. Mol. Cryst. Liq. Cryst. 1979, 51, 209-214.

100. Czub, J.; Urban, S.; Dąbrowski, R.; Gestblom, B. Dielectric properties of liquid crystalline isothiocyanato-tolane derivatives with fluorine atom at various lateral positions. Acta Phys. Pol. A 2005, 107, 947-958.

101. Dąbrowski, R.; Dziaduszek, J.; Garbat, K.; Filipowicz, M.; Urban, S.; Gauza, S.; Sasnouski, G. Synthesis and mesogenic properties of three and four-ring compounds with a fluoroisothio-cyanatobiphenyl moiety. Liq. Cryst. 2010, 37, 1529-1537.

102. Szczucinski, Ł.; Dąbrowski, R.; Urban, S. Synthesis and mesogenic properties of fluorosubstituted isothiocyanatoterphenyls. Military University of Technology, Warsaw, Poland. Unpublished work, 2013.

103. Parish, A.; Gauza, S.; Wu, S.T.; Dziaduszek, J.; Dabrowski, R. New fluorinated terphenyl isothiocyanate liquid crystal single compounds and mixtures. Mol. Cryst. Liq. Cryst. 2008, 489, 22-39.

104. Aziz, N.; Kelly, S.M; Duffy, W.; Goulding, M. Rod-shaped dopants for flexoelectric nematic mixtures. Liq. Cryst. 2009, 36, 503-520.

105. Boller, A.; Cereghetti, M.; Scherrer, H. Synthesis and mesomorphic properties of diphenyl-pyrimidines and biphenylyl-pyrimidines. Z. Naturforsch B 1978, 33, 433-438.

106. Goulding, M.; Greenfield, S.; Parri, O.; Coates, D. Liquid crystals with a thiomethyl end group: Lateral fluoro substituted 4-(trans-4-(n-propyl)cyclohexylethyl-4'-thiomethylbiphenyls and 4-n-alkyl-4"-thiomethylterphenyls. Mol. Cryst. Liq. Cryst. A 1995, 265, $27-40$.

107. Goto, Y.; Ogawa, T.; Sawada, S.; Sugimori, S. Fluorinated liquid crystals for active matrix displays. Mol. Cryst. Liq. Cryst. 1991, 1-7. 
108. Das, M.K.; Pramanik, A.; Das, B.; Szczuciński, Ł.; Dąbrowski, R. A comparative study of the mesomorphic properties of fluoro-Isothiocyanated and fluorinated terphenyl liquid crystals from birefringence, static dielectric permittivity, splay elastic constant and rotational viscosity measurements. J. Phys. D Appl. Phys. 2012, 45, doi:10.1088/0022-3727/45/41/415304.

109. Chojnowska, O.; Dąbrowski, R. The influence of cyanocompound on liquid crystal blue phase range. Photonics Lett. Pol. 2012, 4, 81-83.

110. Gauza, S.; Parish, A.; Wu, S.T.; Spadło, A.; Dąbrowski, R. Physical properties of laterally fluorinated insothiocyanato phenyl-tolane liquid crystals. Liq. Cryst. 2008, 35, 483-488.

111. Gauza, S.; Zhao, Y.; Le Cor, T.; Wu, S.T.; Ziółek, A.; Dąbrowski, R.; Catanescu, O.; Chien, L.C.; Hsu, C.S. High Figure-of-Merit laterally fluorinated biphenyltolane-isothiocyanates. Mol. Cryst. Liq. Cryst. 2007, 479, 169-179.

112. Kula, P.; Aptacy, A.; Herman, J.; Wójciak, W.; Urban, S. The synthesis and properties of fluoro-substituted analogues of 4-butyl-4'-[(4-butylphenyl)ethynyl]biphenyls. Liq. Cryst. 2013, 40, 482-491.

113. Chodorow, U.; Parka, J.; Kula, P.; Herman, J.; Chojnowska, O.; Dabrowski, R.; Chigrinov, V.G. Terahertz properties of fluorinated liquid crystals. Liq. Cryst. 2013, doi:10.1080/02678292.2013.816793.

114. Hird, M.; Toyne, K.J.; Gray, G.W.; Day, S.E.; McDonnell, D.G. The synthesis and high optical birefringence of nematogens incorporating 2,6-disubstituted naphthalenes and terminal cyano-substituent. Liq. Cryst. 1993, 15, 123-150.

115. Seed, A.J.; Toyne, K.J.; Goodby, J.W.; Hird, M. Synthesis, transition temperatures, and optical properties of various 2,6-disubstituted napthalenes and related 1-benzothiophenes with butylsulfanyl and cyano or isothiocyanto terminal group. J. Mater. Chem. 2000, 10, 2096-2080.

116. Sekine, C.; Fujisawa, K.; Iwakura, K.; Minai, M. High birefringence phenylacetylene liquid crystals with low viscosity. Mol. Cryst. Liq. Cryst. 2001, 346, 711-718.

117. Herman, J.; Dziaduszek, J.; Dąbrowski, R.; Kędzierski, J.; Kowiorski, K.; Dasari, V.S.; Dhara, S.; Kula, P. Novel high birefringent isothiocyanates based on quaterphenyl and phenylethynyltolane molecular cores. Liq. Cryst. 2013, 40, 1174-1182.

118. Zhang, Y.-M.; Wang, D.; Miao, Z.-C.; Jin, S.-K.; Yang, H. Novel high birefringence bistolane liquid crystals with lateral fluorosubstituent. Liq. Cryst. 2012, 39, 1330-1339.

119. Wu, S.T.; Hsu, C.S.; Chuang, Y.Y.; Cheng, H.B. Physical properties of polar bis-tolane liquid crystals. Jpn. J. Appl. Phys. Part 2 2000, 39, L38-L41.

120. Celiński, M.; Urban, S.; Chojnowska, O.; Kula, P.; Dziaduszek J.; Dąbrowski, R. Compounds with low relaxation frequency and dual frequency mixtures useful for active matrix addressing. Liq. Cryst. 2013, doi:10.1080/02678292.2013.813085.

121. Xianyu, H.; Liang, X.; Sun, J.; Wu, S.T. High performance dual frequency liquid crystal compounds and mixture for operation at elevated temperature. Liq. Cryst. 2010, 37, 1493-1499.

122. Gauza, S.; Zhao, Y.; Le Cor, T.; Wu, S.T.; Dziaduszek, J.; Sasnouski, G.; Dabrowski, R.; Chien, L.C. Enhancing birefringence by doping fluorinated phenyltolanes. J. Disp. Technol. 2006, 2, 327-332. 
123. Liao, Y.M.; Chen, H.L.; Hsu, C.S.; Gauza, S.; Wu, S.T. Synthesis and mesomorphic properties of super high birefringence isothiocyanato bistolane liquid crystals. Liq. Cryst. 2007, 34, 507-517.

124. Gauza, S.; Wen, C.H.; Wu, S.T.; Janarthanan, N.; Hsu, C. Super high birefringence isothiocyanto biphenyl-bistolane liquid crystals. Jpn. J. Appl. Phys. 2004, 43, 7634-7638.

125. Sekine, C.; Konya, N.; Minai, M.; Fujisawa, K. Synthesis and properties of high birefringence liquid crystals: Thiophenylacetylene and benzothiazolylacetylene derivatives. Liq. Cryst. 2001, 28, 1361-1367.

126. Sekine, C.; Ishitobi, M.; Iwakura, K.; Minai M.; Fujisawa, K. Novel high birefringence dibenzothiophenylacetylene liquid crystals. Liq. Cryst. 2002, 29, 355-367.

127. Stolarz, Z.; Dąbrowski, R.; Parka, J.; Huang, X.; Lapanik, W. Low viscosity mixtures for TN and STN displays, P. Soc. Photo-Opt. Ins. 2000, 4147, 41-48.

128. Gauza, S.; Kula, P.; Dąbrowski, R.; Sasnouski, G.; Lapanik, V. High optical anisotropy nematic single compounds and mixtures. Trans. Electr. Electron. Mater. 2012, 13, 2-5.

129. Reuter, M.; Vieweg, N.; Fisher, B.M.; Mikulicz, M.; Koch, M.; Garbat, K.; Dabrowski, R. Highly birefringent, low-loss liquid crystals for terahertz applications. APL Mater. 2013, 1, 012107:1-012107:7.

130. Nowinowski-Kruszelnicki, E.; Jaroszewicz, L.; Raszewski, Z.; Soms, L.; Piecek, W.; Perkowski, P.; Kędzierski, J.; Dąbrowski, R.; Olifierczuk, M.; Garbat, K.; et al. High birefringence liquid crystal mixtures for electro-optical devices, Liquid crystal cell for space-borne laser rangefinder to space mission applications. Opto-Electron. Rev. 2012, 20, 31-38.

131. Wu, S.T. Birefringence dispersions of liquid-crystals. Phys. Rev. A 1986, 33, 1270-1274.

132. Li, J.; Wu, S.T.; Brugioni, S.; Meucci, R.; Faetti, S. Infrared refractive indices of liquid crystals. J. Appl. Phys. 2005, 97, 073501:1-073501:5.

133. Reuter, M.; Garbat, K.; Vieweg, N.; Fischer, B.M.; Dabrowski, R.; Koch, M.; Dziaduszek, J.; Urban, S. Terahertz and optical properties of nematic mixtures composed of liquid crystal isothiocyanates, fluorides and cyanides. J. Mater. Chem. C 2013, 1, 4457-4463.

(C) 2013 by the authors; licensee MDPI, Basel, Switzerland. This article is an open access article distributed under the terms and conditions of the Creative Commons Attribution license (http://creativecommons.org/licenses/by/3.0/). 